\title{
La escritura visigótica publicitaria en la provincia de Burgos*
}

\author{
Visigothic writing as publicity in the province of Burgos
}

\author{
Alejandro García MoRILlA**
}

\begin{abstract}
RESUMEN
La producción epigráfica es producto de la actividad publicitaria llevada a cabo en el conjunto de talleres de una determinada sociedad, en un determinado momento y en una determinada geografía. Durante los Ss. VIII-XII, en la actual provincia de Burgos, se llevó a cabo la materialización de gran cantidad de "objetos publicitarios" de los que hemos conservado noticia de aproximadamente medio centenar. Una serie de

acontecimientos políticos, religiosos y sociales han condicionado la producción de un Corpus epigráfico rico en matices y peculiaridades que lo convierten en uno de los más significativos de la Península. Su génesis, forma y tradición epigráfica y, sobre todo, su escritura son claves para ahondar en el conocimiento de la historia de esta provincia. En efecto, la escritura como medio de la materialización de un mensaje aparece aquí como el mejor reflejo de la actividad comunicadora de la sociedad burgalesa del momento.
\end{abstract}

PALABRAS CLAVE

Epigrafía medieval, paleografía, visigótica, Burgos.

\begin{abstract}
Epigraphical production is the result of the action of publicity carried out in all the workshops of a given society, at a given time and in a given place. In the province of Burgos, from the eighth to the twelfth centuries, a great number of "advertising objects" were created, information of which has survived for about fifty of them. A series of political, religious and social events conditioned the production of an epigraphical corpus rich in nuances and specificities that makes it one of the most noteworthy in the Peninsula. Its genesis, form, epigraphical tradition and especially, its writing are essential elements that increase our knowledge of the history of this province. Indeed, writing as a means of forging a message appears to be the best reflection of the communicative activity of society in Early Medieval Burgos.
\end{abstract}

\section{KEY WORDS}

Medieval Epigraphy, Palaeography, Visigothic, Burgos

* Fecha de recepción del artículo: 2011-12-2. Fecha de aceptación del artículo: 2011-12-19.

** Universidad de León. 
«Según las épocas y autores, se la viene considerando con los siguientes nombres: visigoda o visigótica, mozárabe o mozarábica, gótica, toletana e hispánica. El de visigoda o visigótica fue inventado por Mabillón para designar a la escritura que él creía originaria y primitiva del pueblo visigodo, el cual la traería consigo y la implantó en la Península. Mozárabe o mozarábica fue llamada ya en la Edad Media; pero quien modernamente puso el nombre de moda fue Gómez Moreno en varios pasajes de sus obras [...] El nombre de gótica, usado por nuestro eruditos del siglo XVI, es sinónimo de visigótica y no supone relación alguna ni con la primitiva de los godos antes de romanizarse ni con la gótica del siglo XII. Toletana es nombre acuñado en sus respectivas historias por Rodrigo Jiménez de Rada y Lucas de Tuy. Escritura hispánica parece haberla llamado solamente el humanista del siglo XVI, Ángel de Módena»Paleografía y diplomática. (Paleografía y Diplomática, UNED) ${ }^{1}$.

En este párrafo se resume la semántica del calificativo «visigótico» aplicado a la escritura; de esta manera explicamos la primera parte del título de nuestro trabajo. Para mejor entender los otros epítetos — «publicitaria» y «permanente»— debemos remitirnos a las palabras del prof. García Lobo, cuando dice que «entendemos por escritura publicitaria aquélla que se usa especialmente para destacar y llamar la atención sobre un esrito o parte de él»»2. Si a éstas añadimos las de R. Favreau para definir la inscripción — «ce qui est écrit sur un monument ou un objet donné, en vue d'une publicité universelle et durable»3- vemos que nos situamos plenamente en el campo de las inscripciones. Por lo tanto vamos a tratar de la escritura de las inscripciones visigóticas de la actual provincia de Burgos.

La producción epigráfica de Burgos durante este periodo es reflejo de una intensa actividad publicitaria llevada a cabo en grandes y pequeños talleres repartidos de forma extensa por toda la geografía burgalesa.

\section{LAS FUENTES}

Vamos a trabajar con, aproximadamente, medio centenar inscripciones. De ellas en la actualidad sólo se conservan 30 que constituirán la base firme y segura de cuanto digamos aquí. Sin embargo entendemos que el panorama puede completarse con otras que estamos autorizados a utilizar, cierto que con cautelas, por haber desaparecido, pero cuyos textos conocemos por las llamadas «copias literarias» y sabemos por su cronología o por descripciones de los autores que las estudiaron que pertenecían a la época que nos ocupa. Un ejemplo podría ser el Monumentum primae petrae que dejó constancia del inicio de las obras del Monasterio de San Pedro de Arlanza de 1080 (Ap. № 5). Actualmente desaparecido. Dejamos,

\footnotetext{
1 MARÍN, T., RUIZ ASENCIO, J. M., et alii, Paleografía y Diplomática, Universidad Nacional de Educación a Distancia, Unidad 1, Madrid 1997, p.113.

2 GARCÍA LOBO, V., La escritura visigótica publicitaria. Paleografía I: La escritura en España hasta 1250: Boletín de la Sociedad Española de Ciencias y Técnicas historiográficas, Burgos 2008, p. 66

3 FAVREAU, R., Les inscriptions medievales, Turnhout 1976, p. 16
} 
en cambio, al margen aquellas «copias» que, a pesar de que su fecha corresponde a nuestro abanico cronológico, fueron realizadas después con otro tipo de escritura; puede tratarse de originales tardíos o de copias epigráficas, cuestión que no nos corresponde resolver ahora 4 . A este conjunto pertenece gran parte de los Epitaphia del claustro de Santo Domingo de Silos, siendo en su mayoría copias de obituario del S. XIII en escritura gótica.

Desde el punto de vista cronológico nuestras inscripciones van desde los años centrales del S. IX —el Monumentum Fundationis de la Ciudad de Lara de 862 (867)(Ap. $\left.\mathbf{n}^{\circ} \mathbf{1}\right)^{5}$ — hasta los años centrales del S. XII en los ejemplos más tardíos, como el Monumentum Plantationis (Aedificatinis $\left.{ }^{6}\right)($ Ap. $n=15)$, de la iglesia de la Inmaculada Concepción de Crespos.

\section{EL PROCESO PUBLICITARIO: GÉNESIS DE LAS INSCRIPCIONES}

Si bien es cierto que nuestro propósito es el estudio de la escritura de estas inscripciones, no lo es menos que aquélla, la escritura, viene muy condicionada por los factores que intervienen en su génesis ${ }^{7} \mathrm{y}$, especialmente, por los que intervienen en la conscriptio. Es lógico; en la conscriptio, o materialización del mensaje epigráfico, tiene lugar la llamada translitteratio que es el procedimiento por el que el texto previamente redactado en escritura ordinaria sobre un trazo de pergamino

\footnotetext{
4 García Lobo y Martín López definen este tipo de textos como «aquella inscripción cuyo texto llegó a nosotros sobre un soporte distinto de aquél para el que fue redactado y ejecutado por el rogatario. A su vez distinguiremos entre copias epigráficas, copias de obituario, copias literarias y renovaciones". Cf. GARCÍA LOBO, V., y MARTÍN LÓPEZ, M. E., De epigrafía medieval. Introducción y álbum, León 1995, p. 42

5 Para este estudio hemos dejado al margen una serie de inscripciones de polémica cronología, cuya escritura debería ser objeto de un estudio pormenorizado de conjunto. Entre ellas destaca la Suscriptio de la ermita de Siero de Valdeteja, sobre la que el Prof. Fernández Flórez ha realizado un concienzudo trabajo, concluyendo que se trata de una inscripción de la centuria anterior a la fecha que hoy podemos leer, y por tanto sus caracteres gráficos serían más próximos al alfabeto visigodo, que al alfabeto visigótico, a pesar de que la actual fecha (777), la situaría en el ámbito cronológico de ésta última. Cf. FERNÁNDEZ FLÓREZ, J. A., La elaboración de los documentos en los Reinos Hispánicos Occidentales (Ss. VI-XIII): discurso de ingreso en la academia burgense de Historia y Bellas Artes, Institución Fernán González, Burgos 2002, p. 40.

6 Esta inscripción es uno de los ejemplos epigráficos más interesantes del Corpus de inscripciones medievales de esta provincia. Sólo guarda cierta relación con otras dos inscripciones —una en el monasterio de Santa María de Carrizo y otra en San Clemente de Nolay-donde se habla de la plantación de huertos y árboles. Debido a su controvertido texto, le hemos dedicado un artículo que trata se sugerir la posible motivación de estos textos, así como proponer una nueva tipología para este tipo de inscripciones, que en última instancia podríamos denominar Monumentum Aedificationis. Cf. GARCíA MORILLA, A., La enigmática inscripción de la iglesia de la Inmaculada Concepción de Crespos: Homenaje al Prof. D. José Manuel Ruiz Asencio (prensa).

7 Remitimos al trabajo del Prof. García Lobo para el centenario de la cátedra de epigrafía de la Universidad Complutense, para un estudio pormenorizado de la génesis de las inscripciones medievales. Cf. GARCíA LOBO, V., La epigrafía medieval. Cuestión de método: Centenario de la cátedra de «Epigrafía y Numismática» Universidad Complutense de Madrid 1900/1 - 2000/1, Madrid 2001, pp. 88-96
} 
—en este momento en papel no estaba aún difundido — se copia sobre la superficie epigráfica en escritura publicitaria mediante el carbón, la tiza, la punta seca o el pincel; ésta será la escritura que llegue hasta nosotros, ocasionalmente modificada por el lapicida en el proceso de grabación de lo escrito en fase anterior ${ }^{9}$. Pero no sólo esto; en la génesis intervienen otros factores -autor y destinatario de la inscripción- que cada uno a su modo y de muy diversa manera van a condicionar la propia escritura. En el autor tiene su origen intelectual en mensaje epigráfico; y su condición social también exigirá una escritura determinada o, al menos, un mayor o menor cuidado en su ejecución. También el destinatario, en cierto modo, influirá en la escritura de acuerdo con su mayor o menor grado de alfabetización, de acuerdo con sus circunstancias sociales o religiosas.

El autor de las inscripciones burgalesas de este periodo pertenece, fundamentalmente, al estamento eclesiástico; éste, dada su misión evangelizadora, es el que más necesidad tenía de emitir mensajes religiosos a sus fieles o a los miembros de su comunidad religiosa. La prof. Martín López ya nos advertía que «durante la Edad Media la producción epigráfica estuvo ligada, directa o indirectamente, al ámbito eclesiástico ${ }^{10}$. Por ello, y de forma genérica, podemos decir que el autor de las inscripciones era el obispo, el abad o el prior de un monasterio como máxima autoridad ${ }^{11}$, o los simples sacerdotes; más raramente, los laicos.

Sin embargo no resulta fácil saber quién es el autor concreto de la inscripción determinada, ya que raramente se deja constancia de su nombre o condición. Quizá el ejemplo más representativo con el que cuenta la provincia de Burgos de autor expreso en la inscripción sea la Roboratio del cáliz de Silos que manda hacer —fecit ${ }^{12}$ — el abad Domingo en el S. XII (Ap. no 4).

8 No obstante no sería descabellado pensar que en el monasterio de Silos, al menos a partir del siglo $\mathrm{XI}$, se redactaran estos textos epigráficos previos sobre papel habida cuenta de que se utilizó para la confección de códices.

${ }_{9}$ Cf. GARCÍA LOBO, V., Scribere, ordinare, sculpere au Moyen Âge (III Colloque Internacional d'Épigraphie médiévale, en prensa)

10 MARTÍN LÓPEZ, M. E., Centro escriptorios epigráficos de la provincia de Palencia: De Litteris, manuscriptis, inscriptionibus. Festchrift zum 65. Geburtstag von Walter Koch, herausgegeben von Theo Kölzer, Franz-Albrecht Bornschlegel, Christian Friedl, Georg Vogeler, Wien, 2007, p. 203

11 Por su parte el Prof. García Lobo nos indica, a propósito del epitafio del abad Esteban de Santiago de Peñalba, «como se procedía en los monasterios, de acuerdo con el mandato de los reponsables de los mismos: abades, priores, prepósitos, etc. Por lo tanto hemos de suponer que todas las inscripciones de nuestros monasterios tengan por autores a estas autoridades». Cf. GARCÍA LOBO, V., La epigrafía medieval. Cuestión de método: Centenario de la cátedra de «Epigrafía y Numismática» Universidad Complutense de Madrid 1900/1 - 2000/1, Madrid 2001,p. 89

$12 \mathrm{El}$ valor roborativo del verbo latino fecit, ya ha sido puesto de relieve en numerosas ocasiones. García Lobo y Martín López señalan que «aparecerán roborationes — siempre en los instrumenta-con la formulación indirecta; esto es, mediante el verbo fecit, que en estos casos equivale a fecit fieri». Cf. GARCÍA LOBO, V., y MARTÍN LÓPEZ, M. E., De epigrafía medieval. Introducción y álbum, León 1995, p. 36. Sobre el cáliz de Santo domingo cabe destacar el minucioso estudio de GAUTIERS, M. M., L'atelier diorfevrerie de Silos à l'époque romaine: IX centenario de la consagración de la iglesia y el claustro de Silos, Abadía de Silos 1990, pp. 337-395 
Son pocos los ejemplos donde encontramos a un laico como autor de una inscripción. Este sería en caso del anteriormente citado, Monumentum Fundationis de la Ciudad de Lara de 862 (Ap. no 1), cuyos autores - Guillermo y Federicoson los maestros de la obra y su procedencia parece alejada de un centro monástico ${ }^{13}$; o la Suscriptio de la obra del monasterio de San Pedro de Arlanza de 1080 (Ap. no 6) -actualmente desaparecida- donde Guillermo y su padre Osten suscriben la obra, y como elemento de doble datación utilizan la fecha y el abadiazgo del abad Vicente ${ }^{14}$, lo que nos indica que se trata, también, de dos maestros de obra laicos que suscriben la obra una vez terminada.

El receptor del mensaje epigráfico es a quien llamamos destinatario. El destinatario de la inscripción es múltiple ${ }^{15}$ : por tanto es receptor de estos textos epigráficos todo aquel lector — universalidad — que a lo largo del tiempo — perdurabilidad- acceda a la inscripción.

El lazo de unión entre ambos interlocutores es el que llamamos Rogatario; es el encargado de materializar el mensaje. Tan difícil como identificar al autor de las inscripciones resulta identificar al rogatario, pues tampoco es frecuente que dejen constancia expresa de su labor. Sin embargo contamos con un precioso ejemplo en la ermita de San Millán de Hortigüela fechado entre los años finales de S. XI y los inicios del S. XII (Ap. no 9). En la inscripción encontramos al maestro Pedro suscriptor de la obra y a Juan —rogatario-que lo escribión ${ }^{16}$.

Lo mismo que en el caso de los documentos, no se puede hablar del rogatario de las inscripciones sin advertir, por un lado, que éste puede ser individual y múltiple. En el primer caso, una sola persona ejecutará el largo proceso de materialización de la inscripción, mientras que en el segundo intervendrán varias personas especializadas en cada una de las tareas de ese proceso. También hay que advertir que el rogatario -individual o colectivo- trabajará en centros especializados que faciliten su labor: se trata de los talleres o scriptoria epigráficos, de cuya mejor

${ }^{13}$ Hemos de decir que el padre Flórez, quien sí vio la inscripción, asegura que se trata de un epígrafe realizado con posterioridad a los datos que recoge, con lo que su credibilidad queda disminuida, así como la trascendencia de los personajes que recoge. Cf. FLÓREZ, E., España Sagrada, XXVII, Madrid 1772.

${ }^{14}$ La utilización del abadiazgo como método de datación es un recurso frecuente en epigrafía para reforzar la credibilidad del texto publicitado. En este caso comprobamos que el abadiazgo de Vicente I comprende los años 1074-1096, lo que concuerda con la fecha de la inscripción. Además nos indica que el autor es un laico — dos en este caso - ya que el abad, máxima dignidad del monasterio, y autor habitual de las inscripciones se utiliza en la data únicamente como elemento validador. Cf. SAN MARTíN, L., Monasterios. Arlanza, DHEE, Madrid 1973, p. 1518

15 La propia naturaleza de la inscripción — publicidad universal y permanente- exige que el destinatario sea múltiple y no individual y concreto como lo es el documento, pongamos por caso.

16 Agradecemos la lectura e interpretación de esta inscripción al Prof. García Lobo, quien además de interpretar el verbo «titulabit», puso en relación esta inscripción con otras análogas donde el rogatario deja su firma precedido por verbos como notuit, scripsit, fecit. 
o peor dotación dependerá en gran medida el resultado final de su trabajo y, por lo tanto, la eficacia del mensaje propuesto en la inscripción ${ }^{17}$.

Hablábamos del largo proceso de materialización de las inscripciones. En efecto, la conscriptio o ejecución de una inscripción requiere una serie de tareas cuya observancia dará como resultado una inscripción técnicamente acabada, de aspecto armónico, caligráficamente correcta, que cumplirá todos los requisitos de la publicidad universal y permanente que pretende la inscripción.

La primera de esas tareas es la confección de la minuta, entendida ésta como la anotación más o menos breve, donde se recogen los datos fundamentales de cada inscripción ${ }^{18}$. En la provincia de Burgos no tenemos evidencias de que se hayan conservado minutas en este periodo medieval ${ }^{19}$.

La segunda es la redacción del texto definitivo: lo que llamamos el mundum o engrossatio. En esta fase se completan los datos de la minuta a través de una serie de formularios. La existencia de este tipo de formularios, aunque no conservemos ninguno en sentido estricto, se deduce por la repetición de fórmulas en muchas inscripciones, sobre todo en los Epitaphia. En estos casos la minuta podría consistir en el nombre del difunto y la fecha de defunción y la parte formulística sería en resto del texto que se repite en no pocos de ellos. Tal sería el caso de los epitaphia de la sierva de Dios Godo, en el sepulcro de Mudarra de la Catedral de Burgos de 1105 (Ap. no 10), el de Jimeno en Hormicedo de 1139 (Ap. no 13) o el del Munio González de s. XI (Ap. no 8) conservado en el Museo de Burgos. En los tres casos vemos cómo se incluyen fórmulas habituales, tales como famulus Dei, acompañadas por el mismo verbo notificativo -obiit- y completados después con la data. Lo que nos hace pensar que sólo fueron entregados en la minuta los nombres y las fechas de defunción y se les aplicaron formularios más o menos estándar a los tres.

De acuerdo con la extensión del texto ya redactado in mundum, y con la función concreta que se quiere dar al letrero, el «especialista» procederá a la elec-

17 La Prof Martín López hace un perfecto estudio en el que distingue entre tres tipos de centros escriptorios epigráficos: ocasionales, monásticos y profesionales. La mayor o menor pericia encontrada en la inscripción en relación al texto, al surco, al remate, la materia escriptoria está ligada a la actividad más o menos profesionalizada de estos centros. De la misma manera, los talleres más especializados cuentan con diferentes profesionales encargados de cada una de las fases de la Conscriptio epigráfica. Para un estudio más detallado Cf. MARTíN LÓPEZ, Ma․ E., Centro escriptorios epigráficos de la provincia de Palencia: De Litteris, manuscriptis, inscriptionibus. Festchrift zum 65. Geburtstag von Walter Koch, herausgegeben von Theo Kölzer, Franz-Albrecht Bornschlegel, Christian Friedl, Georg Vogeler, Wien, 2007, pp.203-227

18 GARCÍA LOBO, V., y MARTÍN LÓPEZ, Ma․ E., De epigrafía medieval. Introducción y álbum, León 1995, pp. 28-29

${ }_{19}$ Burgos no es una excepción. Para el periodo medieval, de todas las provincias que se están recogiendo en el Corpus Inscriptionum Hispaniae Mediaevalium, solamente en el corpus segoviano se ha encontrado un posible ejemplo. Se trata de la Piedad de Fernando Gallego, pintura sobre tabla conservada en el Museo del Prado y donde los análisis de reflexografía muestran la minuta de la inscripción. Cf. FINALDI, G., y GARRIDO, C., El trazo oculto: dibujos subyacentes en pinturas de los siglos XV y XVI. EXposición Museo Nacional del Prado, del 20 de julio al 5 de noviembre de 2006, Madrid 2006. 
ción del soporte: piedra, mármol y metales fundamentalmente, a no ser que el propio objeto que portará la inscripción ya se lo dé elegido.

Escogido el soporte, entra en juego el experto en trasladar el texto redactado en materia ordinaria a la materia epigráfica, operación que conocemos con el nombre genérico de ordinario — de ahí que se le conozca como ordinatorpero que consiste en una serie de operaciones distintas pero complementarias: preparación del espejo epigráfico, la impaginatio, y la translitteratio ${ }^{20}$. Muy raramente quedan huellas directas de estas operaciones, si no es en inscripciones inacabadas. Tal sería el Monumentum Aedificationis de San Millán de Lara de preciosa escritura carolina, en que pueden apreciarse restos del carbón con que fueron ejecutados los distintos signos gráficos:

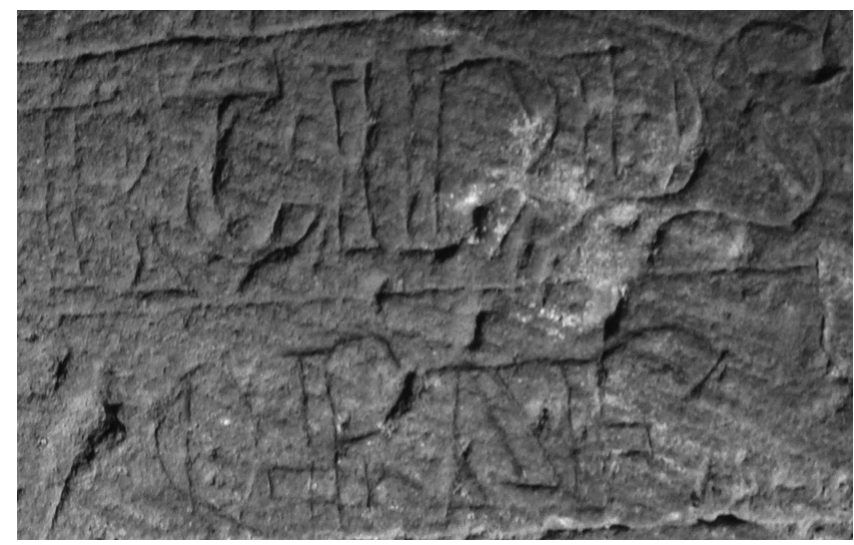

Sin embargo, las huellas indirectas, como resultado del proceso, es la distribución del texto en el campo epigráfico, el reglado, y la propia escritura sobre todo. Estas huellas pudieron ser alteradas, cierto que en una mínima parte cuando lo fueron, por el lapicida en el proceso de la incisio ${ }^{21}$.

El último paso es la grabación del texto que conocemos como incisio. La mayor o menor capacidad del lapicida para esculpir las letras dará por resultado inscripciones más o menos toscas. La Suscriptio de la iglesia de Santa Eulalia de S. X (Ap. no 2), es un buen ejemplo de un lapicida poco acostumbrado al trabajo sobre piedra. Las letras son de desigual tamaño, no respeta líneas de pautado e incluye abreviaturas propias de la escritura minúscula documental, por lo que parece tratarse de un taller ocasional más acostumbrado a la factura de documento o códices:

20 Sobre esto cf. GARCÍA LOBO, V., Scribere, ordinare, sculpere au Moyen Âge: Actas del III Coloquio Internacional de Epigrafía Medieval (Poitiers 2009), de próxima aparición.

${ }^{21}$ Cf. Al respecto GARCÍA LOBO, V., y MARTÍN LOPEZ, Ma․ E., Errores de rogatario 


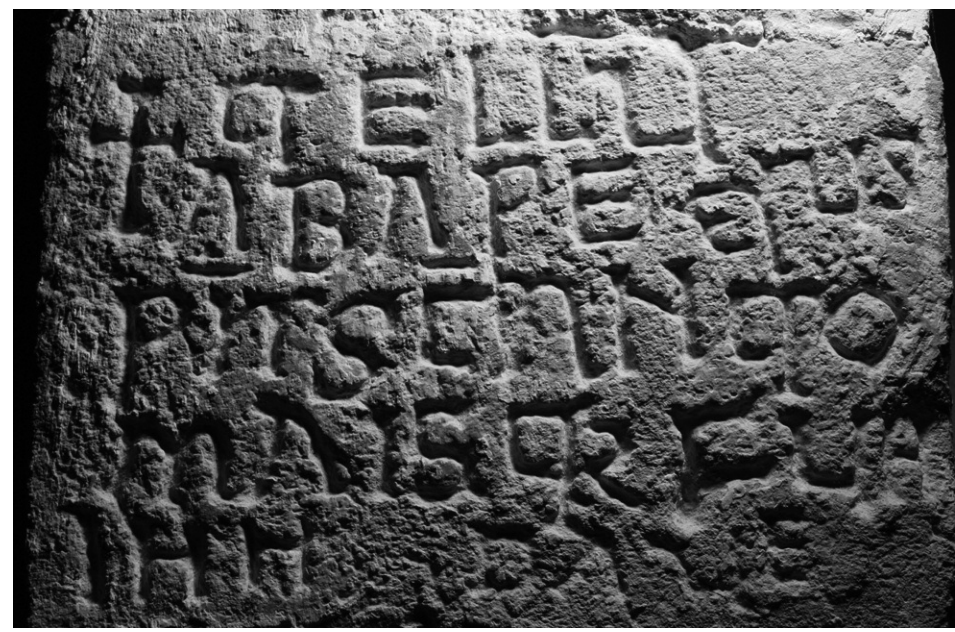

Por el contrario contamos con un Consecratio de 1132 (Ap. $n$ ํ 12) de la misma iglesia de Santa Eulalia en Santa Olalla, que encontramos en la sacristía, donde los recursos utilizados por el rogatario y la resolución final de lapicida nos hacen pensar en un taller con cierto desarrollo y unos «técnicos» más habituados ya a este tipo soporte:

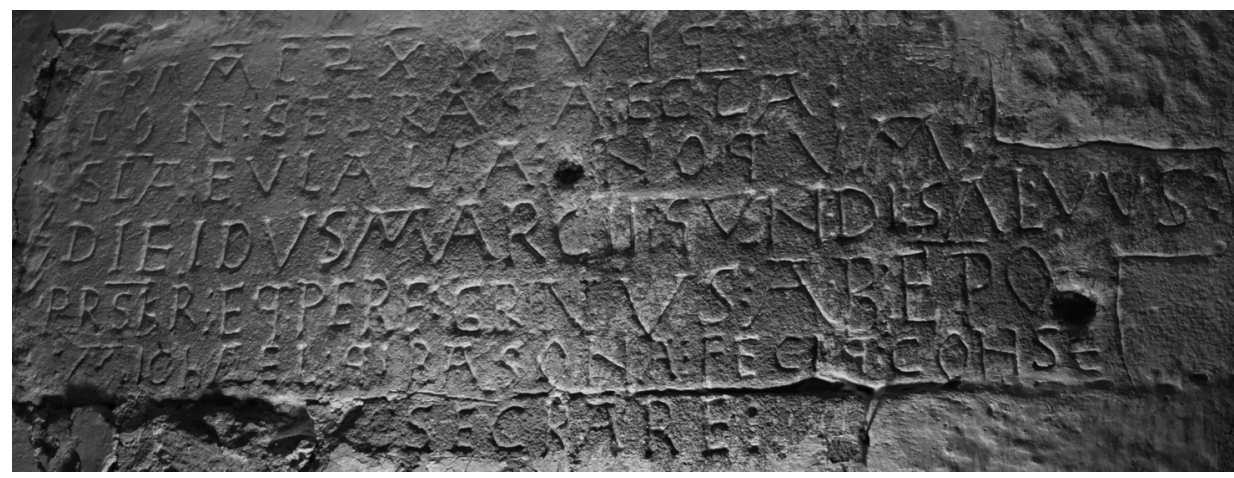

\section{CARACTERES INTERNOS Y CLASIFICACIÓN}

Hemos aludido en más de una ocasión a Epitaphia o a Consecrationes, Monumenta, etc. Parece conveniente que en este apartado hagamos una sucinta clasificación de todo el material objeto de nuestro estudio que facilite posteriores referencias, además de ofrecer un panorama más completo de todo él. Esta 
clasificación se basa fundamentalmente en los caracteres internos, especialmente en la naturaleza del texto y en sus fórmulas ${ }^{22}$.

De acuerdo con esa naturaleza nuestras inscripciones van a ser o librarias ${ }^{23} \mathrm{o}$ diplomáticas. A las primeras pertenecen cinco inscripciones, mientras que a las segundas veintinueve.

Inscripciones librarias. Dentro de este grupo contamos con tres Invocationes, una Hortatio, y una Explanatio.

Inscripciones diplomáticas. Como decíamos, las veintinueve inscripciones diplomáticas se clasifican por su parte en Consecrationes, cuyo verbo notificativo más frecuente suele ser dedicavit; Monumenta que, según el verbo notificativo, serán a su vez aedificationis, plantationis y primae petrae; Epitaphía, divididos en sepulcralia, con verbo notificatio requiescit o necrologica, cuyo verbo notificativo es obiit. También contamos con un Funus, cuyo estado de conservación nos impide concretar más su tipología, y Roborationes, con verbo notificativo fecit o fecit fieri y con Intitulationes donde únicamente consta el nombre del autor de la inscripción o del personaje al que alude.

Véanse los Cuadros que incluimos a continuación:

1. Inscripciones librarias:

\begin{tabular}{|c|c|c|}
\hline TIPOLOGIA & LUGAR & DATA \\
\hline Invocatio & San Miguel de Neila & 1087 \\
\hline Invocatio & San Miguel de Neila & 1087 \\
\hline Invocatio & Pancorbo & S. XI \\
\hline Hortatio & S. Miguel de Neila & 1087 \\
\hline Explanatio & Ael & S. IX-X \\
\hline
\end{tabular}

22 Estos aspectos han venido trabajándose desde hace tiempo por diversos especialistas. García Lobo y Martín López hicieron una primera aproximación en su manual de epigráfica. GARCíA LOBO, V., Y MARTÍN LÓPEZ, Ma․ E., De epigrafía medieval. Introducción y Album, León 1995, p.34-39. Igualmente, le ha dedicado sendos capítulos el prof. Favreau en 1997 en su manual de epigrafía. FAVREAU, R., Épigraphie Médiévale (L'atelier du Médiéviste, 5), Turnhout 1997, pp.91-112, 141-163, 165-182. Igualmente, debemos destacar la síntesis que realiza el propio García Lobo en su trabajo sobre el método epigráfico. GARCÍA LOBO, V., La epigrafía medieval. Cuestión de método: Centenario de la cátedra de «Epigrafía y Numismática» Universidad Complutense de Madrid 1900/1 - 2000/1, Madrid 2001, p. 97

${ }_{23}$ Para esta clasificación y sus características cf. De epigrafía medieval. Introducción y Album, pp. 3539 y MARTÍN LÓPEZ, Ma. E., y GARCÍA LOBO, V., La Epigrafía Medieval en España. Por una tipología de las inscripciones: VIII Jornadas Científicas sobre Documentación de la Hispania altomedieval (siglos VI-X), Madrid 2009, pp. 185-213 
2. Inscripciones diplomáticas:

\begin{tabular}{|c|c|c|c|}
\hline TIPOLOGÍA & LUGAR & DATA & V. NOTIFICATIVO \\
\hline M. Fundationis & Ciudad de Lara & $862-867^{*}$ & Fecerunt \\
\hline M. Fundationis & S. Miguel de Neila & 1087 & Fundabit \\
\hline Suscriptio & Santa Eulalia & S. $X$ & Fuit? \\
\hline Suscriptio & Santa Eulalia & S.X & \\
\hline Suscriptio & Valdeteja & S. $X$ & Fecit \\
\hline Suscriptio & S. Pedro de Arlanza & 1080 & Fecerunt \\
\hline Suscriptio & San Millán Hortigüela & Ss.XI-XII & Fecit \\
\hline Suscriptio & Mazariegos $^{24}$ & $1102-1111$ & Fecit \\
\hline Suscriptio & Tartalés de Cilla & S. XII, mediados & Fecit \\
\hline E. Sepulcrale & Hontanas & Ss. VIII-X & \\
\hline E. Sepulcrale & Tartalés de Cilla & Ss. VIII-X & \\
\hline E. Sepulcrale & Busnela de Valdeporres & Ss. VIII-X & \\
\hline E. Sepulcrale & Pancorbo & S. XI & \\
\hline E. Sepulcrale & Valeránica, Munio25 & S. XI & Obiit 26 \\
\hline E. Sepulcrale & $\begin{array}{l}\text { Catedral, S. Mudarra } \\
\text { (San Pedro Arlanza) }\end{array}$ & 1105 & Requiescit \\
\hline Funus & Montesclaros & Ss. IX-X & \\
\hline Funus & Retortilla & S. XI & \\
\hline Intitulatio & San Andrés de Argote & S. $X$ & \\
\hline Intitulatio & San Millán de Lara & S. $X$ & \\
\hline M. Primae Petra & S. Pedro de Arlanza & 1080 & Sumsit \\
\hline M. primae Petra & S. Salvador de Escaño & 1088 & Cepit \\
\hline
\end{tabular}

${ }^{24}$ Se trata de una Suscriptio en una pila bautismal actualmente conservada en el Museo Arqueológico Nacional.

${ }^{25}$ Estela Funeraria de cierto Munio, conservada en el Museo de Burgos, procedente del Monasterio de valeránica o Berlanda.

${ }^{26}$ Se trata de un caso excepcional que consideramos E. sepulcrale a pesar de que el verbo notificativo es Obiit por estar inserto el texto en una losa sepulcral. 


\begin{tabular}{|l|l|l|l|}
\hline \multicolumn{1}{|c|}{ TIPOLOGÍA } & \multicolumn{1}{|c|}{ LUGAR } & \multicolumn{1}{c|}{ DATA } & V. NOTIFICATIVO \\
\hline E. Necrologicum & Valeránica, García ${ }^{27}$ & S. XI & Obiit \\
\hline E. Necrologicum & Hormicedo & 1139 & Obiit \\
\hline Consecratio & Riocavado de la Sierra & 1114 & Dedicavit \\
\hline Consecratio & Rosales & 1122 & Dedicata est \\
\hline Consecratio & Santa Eulalia & 1132 & Fuit consecrata \\
\hline M. Plantationis & Crespos & 1147 & Plantavit \\
\hline Roboratio & Silos, Cáliz & S. XI, mediados & Fecit ${ }^{28}$ \\
\hline
\end{tabular}

\section{LA TRADICIÓN EPIGRÁFICA}

Como objeto escrito que es y, por lo tanto, portador de un texto, la inscripción cuenta también - lo mismo que el documento y el libro — con una tradición textual que hará de ella original, copia, o falsa ${ }^{29}$. Justificamos hacer aquí algunas consideraciones sobre el tema por la necesidad de considerar, sobre todo, aquellas inscripciones no originales en que podemos encontrar contradicción entre los datos históricos y los datos paleográficos. Me parece muy reveladores al respcto estos párrafos del prof. García Lobo:

«Tradicionalmente se viene asignando a cada epígrafe la fecha histórica explícita y, a falta de ésta, se acude a la ayuda de otras, tales como la paleográfica, laq arqueológica, la lingüística, etc. Este método es bueno, pero sólo si se adoptan las debidas precauciones teniendo en cuenta siempre la naturaleza y tipología del epígrafe. La data histórica sólo nos sitúa los hechos cpnsignados en una época determinada; la paleográfica nos fijará la fecha de la ejecución material del epígrafe; la arqueológica nos dará el contexto y entorno en que nació; la filológica nos hablará en todo caso del momento aproximado en que se redactó el texto. Sólo cuando se concluya que todas ellas coinciden y se corresponden podremos decir que estamos ante un epígrafe original $y$, por tanto, plenamente fiable en cuanto a la información histórica, paleográfica, arqueológica o filológica que puede suministrarnos»30.

27 Estela funeraria del confesor García, conservada en el Museo de Burgos, procedente del Monasterio de Valeránica o Berlanda.

28 Se sobreentiende Fecit Fieri

29 Sobre los problemas de la tradición epigráfica cf. De Epigrafía medieval, pp. 41-43, y GARCíA LOBO, V., La analogía en las Ciencias de la Escritura: Homenaje al prof. José Manuel Ruiz Asencio (de próxima aparición).

30 GARCÍA LOBO, V., Las inscripcione medievales de San Isidoro de León. Un ensayo de Paleografía epigráfica medieval: Santo Martino de León (Ponencias del I Congreso Internacional sobre Santo Martino en el VIII Centenario de su obra literaria, 1185-1985), León 1987, pp. 371-398, concretamente p. 380 
En efecto, entre nuestro material contamos con algunas inscripciones en que se dan discrepancias entre la data histórica y la paleográfica. Esta situación se da especialmente en el claustro de Santo Domingo de Silos en el llamado «obituario en piedra»

Los falsos por su parte, son inscripciones cuyo texto no corresponde con realidad alguna. A pesar de ser un tema poco trabajado en nuestra compilación, contamos con algunas inscripciones «bajo sospecha» de falsedad. Este podría ser el caso — siguiendo los apuntes del padre Flórez- del Monumentum fundationis de la Ciudad de Lara de 862 (867) (Ap. no 1). En la noticia que nos da el padre Flórez se nos dice que la inscripción fue realizada tiempo después de los hechos que recoge, sin que los personajes hayan podido ser ubicados, con lo que podríamos estar antes una copia o más bien un falso epigráfico ${ }^{32}$.

Sin embargo, la mayor parte de las inscripciones recogidas son originales; es decir, inscripciones cuyo texto ha llegado hasta nosotros de la misma manera en que fue redactado, transliterado y gravado por primera vez.

\section{LA ESCRITURA}

Como decíamos al principio y refleja el propio título del presente trabajo, la escritura de nuestras inscripciones es la visigótica de los siglos VIII al XII, cuyas características, variedades y matices nos proponemos analizar a continuación ${ }^{33}$. Característica, variedades y matices que van a estar en función de cada calígrafo - translitterator - concreto y del soporte sobre el que ha de escribir, adelantando ya ahora que todas ellas —excepto el cáliz de Santo Domingo, del monasterio de Silos- están trazadas sobre piedra.

De acuerdo con las condiciones culturales, y materiales también, nuestros calígrafos nos van a dar unas inscripciones de cultura urbana o de cultura rural. De tal forma que vamos a descubrir distintos centros escriptorios con una producción epigráfica de características muy similares, no sólo gráficas sino también decorativas, por más que este elemento sea muy escaso y se reduzca a las conocidas hederae.

31 Para un conocimiento exhaustivo de esta epigrafía remitimos al trabajo de GARCíA LOBO, V., La epigrafía del claustro de Silos: El Románico en Silos: I centenario de la consagración de la iglesia y el claustro de Silos. 1088-1988, Silos 1990, pp. 85-98.

${ }^{32}$ FLÓREZ, E., España Sagrada, XXVII, Burgos 1990, p. 619.

33 Sólo disponemos de dos trabajos de conjunto sobre esta escritura: GARCÍA LOBO, V., La escritura publicitaria en la Península Ibérica. Siglos X al XIII: Inschrift und Material. Inschrift und Buchschrift, München 1997 y GARCÍA LOBO, V., La escritura visigótica publicitaria: Paleografía I: La escritura en España hasta 1250, Boletín de la Sociedad Española de Ciencias y Técnicas historiográficas, Burgos 2008, pp. 61-91(en adelante: La escritura visigótica publicitaria)

${ }_{34}$ Pensamos que estas características están convenientemente descritas por el prof. García Lobo en su ya citado trabajo La escritura publicitaria en la Península Ibérica, pp. 155-166 y también en La escritura visigótica publicitaria, pp. 63-91. 


\section{CARACTERÍSTICAS GENERALES ${ }^{34}$}

Como ya señalara en su día el prof. García Lobo, citando a su vez a Millares Car$1 \mathrm{l}^{35}$, «el alfabeto visigótico está compuesto. Como ya hemos dicho, fundalmentalmente de caracteres mayúsculos, que tiene su origen en la capital clásica y en la unicial romana; a éstos se añaden letras minúsculas agrandadas ${ }^{36}$. Sin embargo, a partir de las primeras décadas del siglo XII ya encontramos las primeras influencias carolinas que se manifiestan en el uso de $\mathbf{V}$ por $\mathbf{U}$, la $\mathbf{O}$ circular en lugar de romboidal, $\mathbf{M}$ redondeadas y estilizadas. Algunas de estas evoluciones las podemos ver en la Consecratio de Riocavado de la Sierra de 1114 (Ap. no 11) donde conviven ambas escrituras:

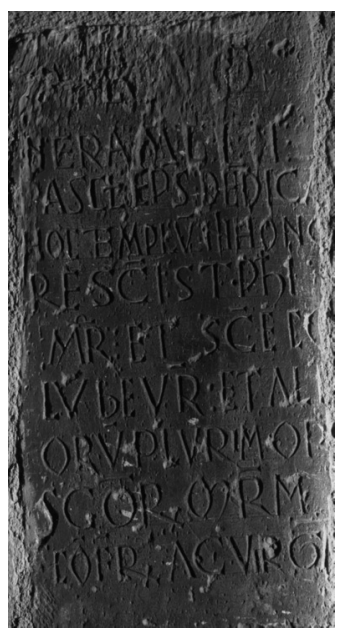

Sin analizar ahora cada una de las letras, nos detendremos en aquellas que, por más características, marcan una diferencia clara con las letras carolinas. Así, tenemos la $\mathbf{A}$ sin trazo horizontal, muy habitual durante todo el periodo. Además tenemos la $\mathbf{D}$ capital o la $\mathbf{M}$ con el primer y último trazo convergentes hacia arriba. Más característica en la $\mathbf{O}$ romboidal o la $\mathbf{R}$ con el último trazo rectilíneo. Aunque quizá sea la letra más representativa la $\mathbf{T}$ con bucle a la izquierda, que llegará a ser copiado posteriormente en alguna inscripción con alfabeto carolino debido, posiblemente, a un gusto estético de un rogatario que conocía la escritura visigótica precedente.

En líneas generales se trata de unas letras cuyo módulo es el doble de alto que de ancho, aunque vemos que esta tendencia se va perdiendo a medida que nos acercamos al S. XII. Véase el cuadro adjunto, formado a partir de la Suscriptio de Tartalés de Cilla (Ap. no 14), la Suscriptio de Santa Eulalia (Ap. no 2), la Con-

\footnotetext{
35 MILLARES CARLO, A., Tratado de Paleografía española, T.I, 3ª ed., Madrid 1983, p. 78

36 GARCÍA LOBO, V., La escritura publicitaria en la Península Ibérica. p. 158
} 
secratio de Santa Eulalia (Ap. no 12) y el Monumentum Primae Petrae de San Salvador de Escaño (Ap. no 7), de diferentes cronologías:

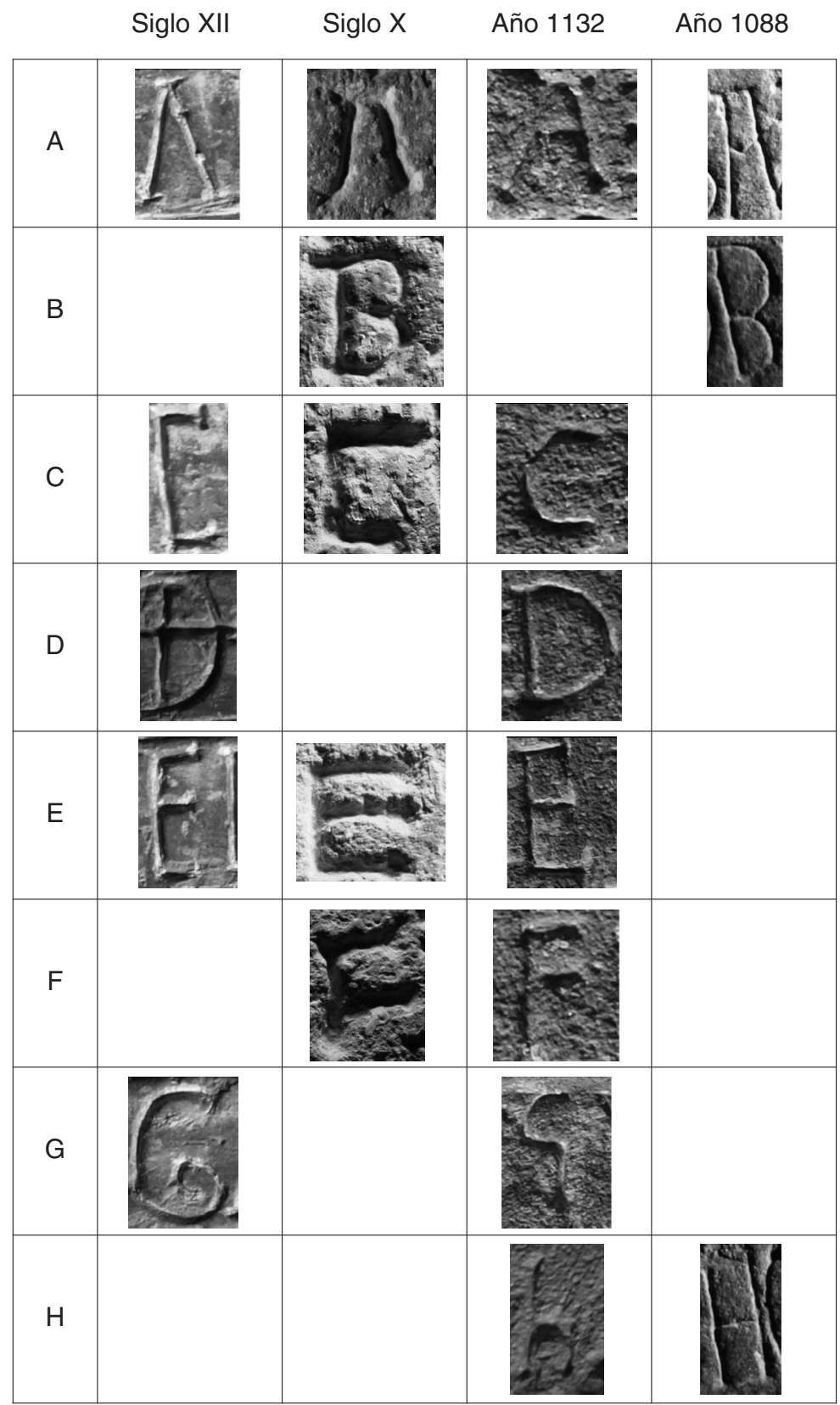


Siglo XII Siglo X Año 1132 Año 1088

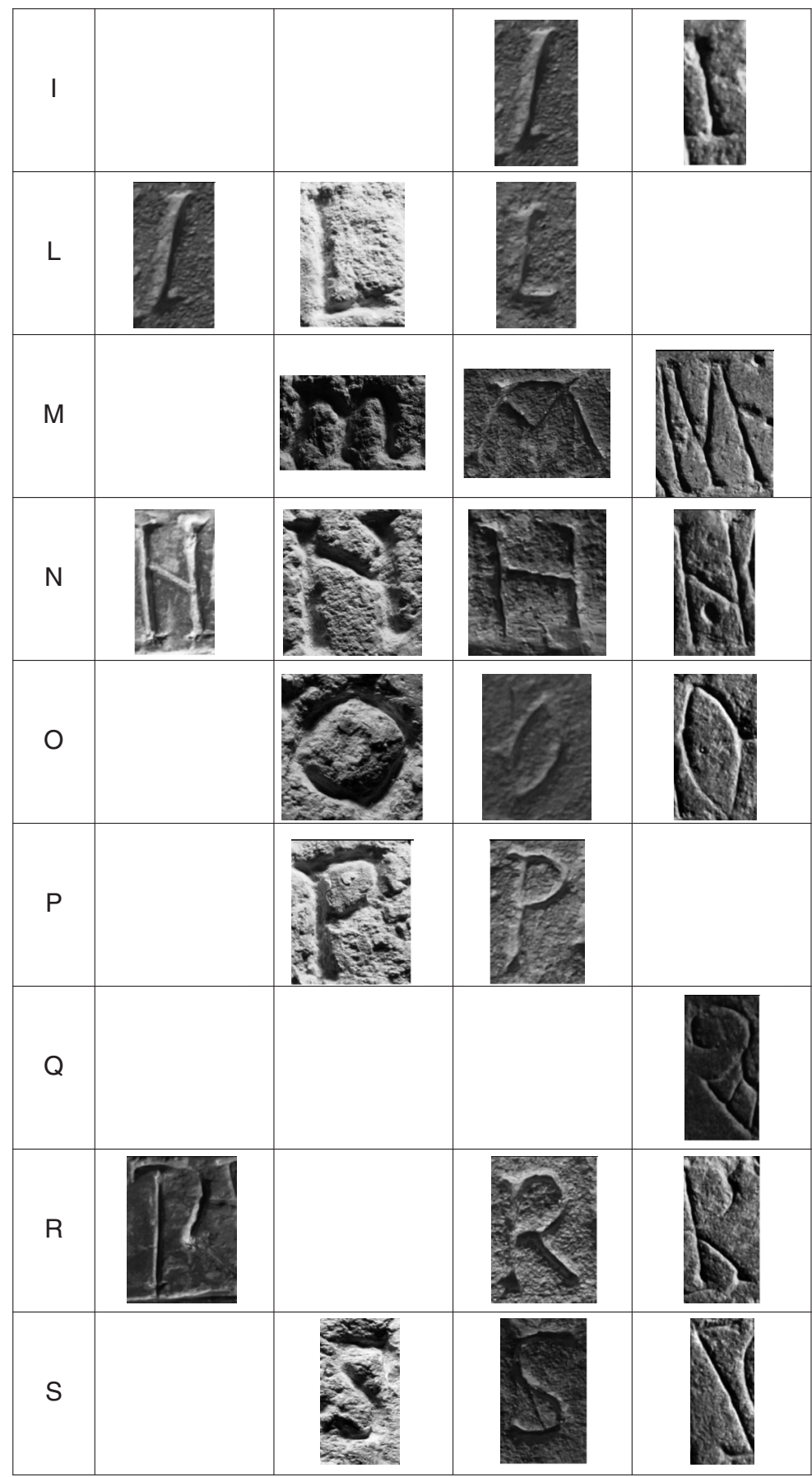




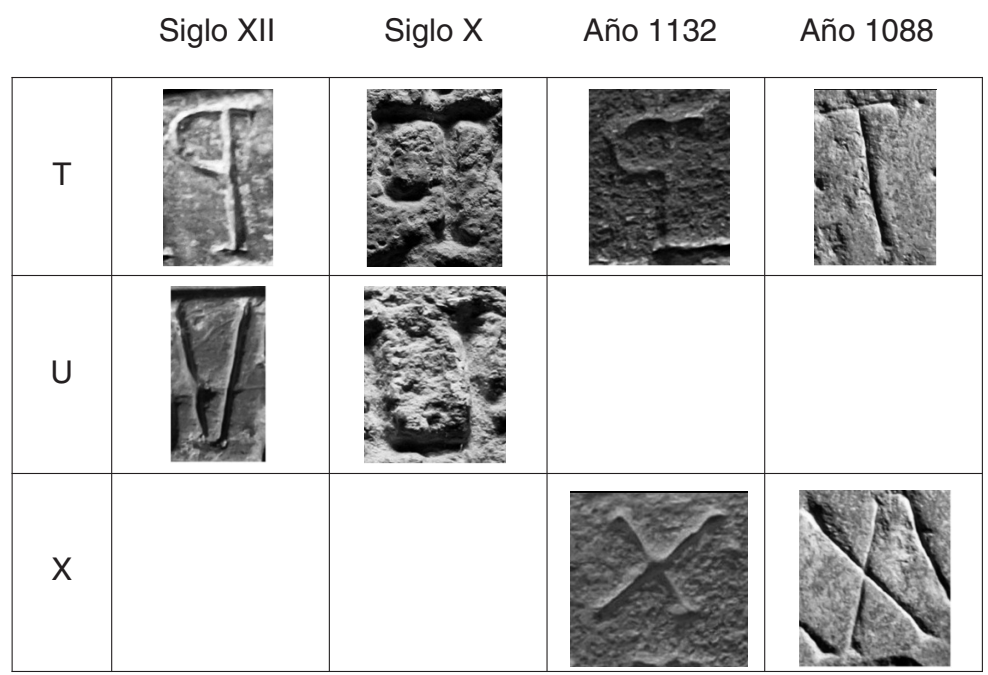

El peso de las mismas varía notablemente de unas inscripciones a otras. Normalmente, en inscripciones procedentes de talleres habituales, encontramos letras más ligeras, esbeltas y bien definidas. Por el contrario, en aquellos centros ocasionales, el peso de las mimas suele ser más profundo y ancho ${ }^{37}$.

Como ejemplo de escritura tosca, de módulo alargado y letras pesadas, están las dos Suscriptiones — una de ellas inacabada - de la Iglesia de Santa Eulalia, que hemos presentado en el alfabeto de la segunda columna.

Sin embargo, la escritura que encontrábamos en San Salvador de Escaño, tiene un modulo visigótico más riguroso de 2:1, es decir, letras el doble de altas que de anchas, y se trata de una escritura mucho más ligera. La utilización, como veremos, de letras nexadas, cruzadas e inscritas, nos habla de un rogatario avezado y de un centro habituado a trabajar en epígrafes.

Por lo que se refiere a las abreviaturas, como también señalara en su día el prof. García Lobo, «lo primero que se advierte tras el examen de las abreviaturas

37 De nuevo hemos de volver sobre el trabajo de Martín López para analizar, esta vez desde el punto de vista de la escritura, la importancia de los «centros Scriptoria». De los centros ocasionales dice: «Sus inscripciones suelen ser torpes tanto en escritura como en aspecto y los textos, generalmente breves». De los centros monásticos nos dice: «...producción epigráfico por y para un monasterio... inscripciones más cuidadas que las anteriores, su rogatario —redactor y ordinator- procede del scriptorium y a veces también el lapicida». En relación con los centros profesionales - que asocia talleres del Románico- dice: «La materialización de la inscripción corre a cargo, en todos los casos, del taller escultórico». Estos últimos no los encontraremos, en líneas generales, en nuestras inscripciones visigóticas, salvo en el caso del cáliz de Silos, cuya materialización epigráfica está asociada a talleres avezados. Cf. MARTíN LÓPEZ, Mā. E., Centro escriptorios epigráficos de la provincia de Palencia: De Litteris, manuscriptis, inscriptionibus. Festchrift zum 65. Geburtstag von Walter Koch, herausgegeben von Theo Kölzer, Franz-Albrecht Bornschlegel, Christian Friedl, Georg Vogeler, Wien, 2007, pp. 204-227. 
visigóticas es que, además de encontrarlas repetidas en uno y otro medio -el epigráfico y el librario- son las mismas de la escritura ordinaria»38. Así pues, vamos a encontrarnos con abreviaturas por contracción, por suspensión y mixtas, señaladas mediante los consabidos signos general y especial de abreviación.

Como ejemplos de abreviaturas por el sistema de contracción citaremos la palabra SANCTI de la Consecratio de Riocavado de la Sierra (Ap. no 11):

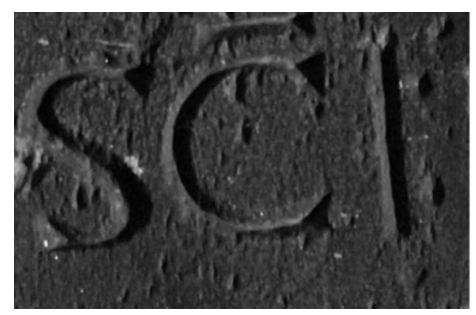

Además de aquellas abreviaturas por suspensión en que falta la nasal final, un ejemplo típico puede ser el de la palabra, TEMPLVM, también tomada de la misma inscripción de Riocavado de la Sierra (Ap. no 11).

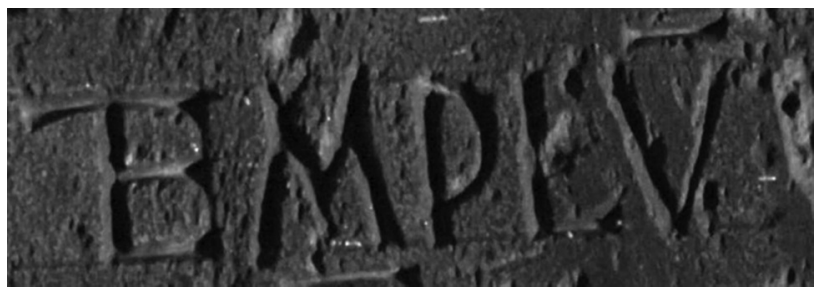

También encontramos una palabra en esta inscripción con abreviatura por el sistema mixto CONFESORUM:

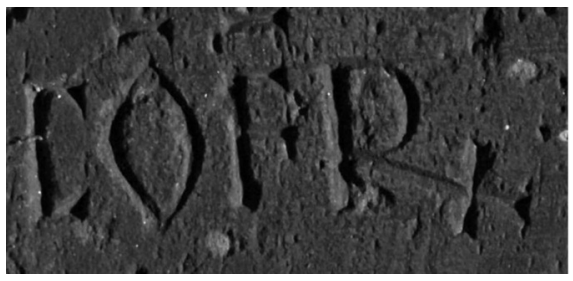

El signo de abreviación más utilizado es el general colocado sobre la letra a que afecta, que se reduce a una raya más o menos recta y regular:

338 Cf. GARCÍA LOBO, V., La escritura visigótica publicitaria: Paleografía I: La escritura en España hasta 1250: Boletín de la Sociedad Española de Ciencias y Técnicas historiográficas, Burgos 2008, p.73 


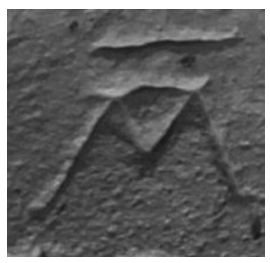

Como signos especiales destaca el trazo vertical que rompe la $\mathbf{R}$ en la palabra Confesorum anterior y que se repite en la palabra Sanctorum de la misma inscripción :
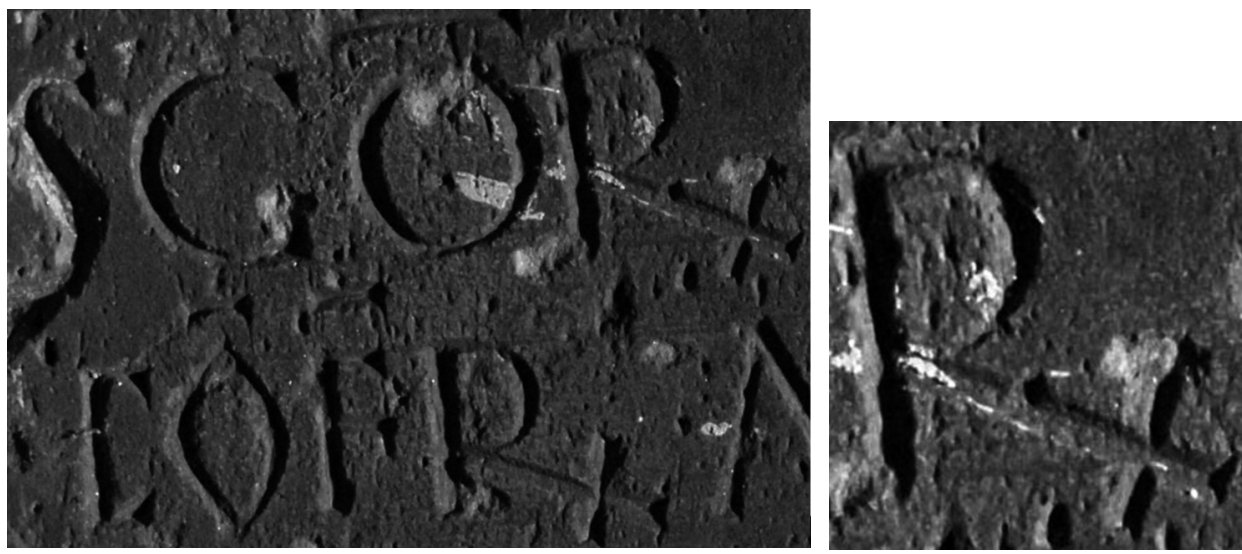

Como elementos gráficos complementarios hemos de destacar la cruz $(+)^{39}$, cuya función primera es, sin duda, la de invocatio cristiana, pero de la que se desprenden efectos decorativos evidentes, tal y como puede apreciarse en la Suscriptio de la iglesia de Santa Eulalia, en Santa Ollalla (Ap. no 2), que vemos abajo:

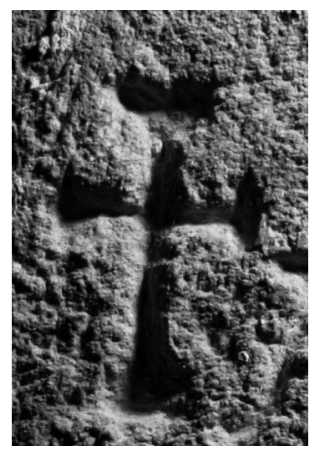

39 GODDARD KING, G., The triumph of the cross. A Note on a mozarabic them: The art Bulletin, Vol. XI, 1929, pp. 317-326 
También, y más importantes como tales elementos, son los signos de separación de palabras. Su utilización y regularidad tiene mucho que ver con el tipo de cultura a que pertenecen las inscripciones, siendo más regulares y frecuentes en las de cultura urbana que en las de cultura rural. Tampoco puede negarse a su presencia y uso unos efectos decorativos, además de la función primera y directa de facilitar la lectura. En este periodo, lo más frecuente es la utilización de tres puntos, como los que vemos en la Consecratio de la iglesia de Santa Eulalia de 1132 (Ap. no 12), que vemos a continuación:

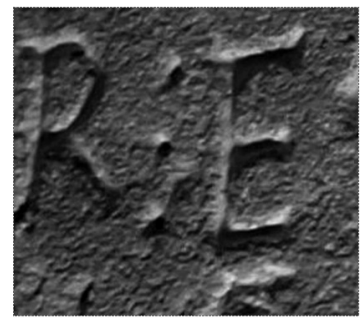

Otro de estos signos complementarios de la escritura es la hederae ${ }^{40}$. Relativamente frecuentes en las inscripciones de esta época, en nuestro caso sólo aparece al final de la Suscriptio de Rodrigo Galeciano en Tartalés de Cilla de mediados de S. XII (Ap. no 14), en la foto, con evidente función de señalar el final del escrito.

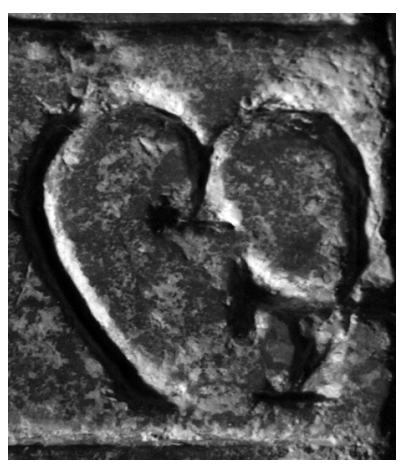

Si cuanto llevamos dicho es común y válido tanto para las inscripciones de cultura urbana como para las de cultura rural, los llamados recursos publicitarios ${ }^{41}$ -nexos, inserciones y cruzamientos - varían de unas a otras, aunque sigue siendo válida en general la doctrina expuesta por García Lobo, cuando dice que su utilización está en relación directa con la mayor o menor disponibilidad de espacio escriptorio.

40 Sobre su uso y funciones, cf. el ya citado trabajo de García Lobo La escritura publicitaria en la Península Ibérica, pp. 165-166

${ }_{41}$ Sobre los recursos publicitarios cf. GARCíA LOBO, V., La escritura publicitaria, p. 154 
Algo parecido podríamos decir de los signos complementarios de la escritura, que generalmente se reducen a los puntos de separación de palabra, cuyo empleo y regularidad va a depender del tipo de inscripción de que se trate.

\section{INSCRIPCIONES DE CULTURA URBANA}

Estas inscripciones «se caracterizan, además, de por su aspecto cuidado y elegante, por su trazo seguro y firme, por la regularidad del modulo de su caracteres, capitales y unciales, por la abundancia de nexos y, sobre todo, por la profusión del empleo de letras inscritas ${ }^{42}$.

Según esto, pertenecerían a este tipo de cultura un importante número de las inscripciones estudiadas. En efecto, observamos en ellas una ordinatrio completa, una caligrafía buena y regular, y un conjunto escrito armónico y agradable a la vista.

Es en ellas donde mejor se aprecian las características de la escritura visigótica, con su módulo alargado en la proporción de 2:1, y donde los recursos publicitarios se emplean también con regularidad: nexos a base de un trazo común para dos letras, inserciones de unas letras en otras - generalmente vocales dentro de consonantes - reduciendo su módulo las primeras, e incluso cruzamientos de unas letras con otras. El mejor ejemplo, quizá, al respecto es la inscripción, tantas veces mentada, de San Salvador de Escaño (Ap. no 7), donde prácticamente la totalidad de sus letras están nexadas, inscritas o cruzadas:

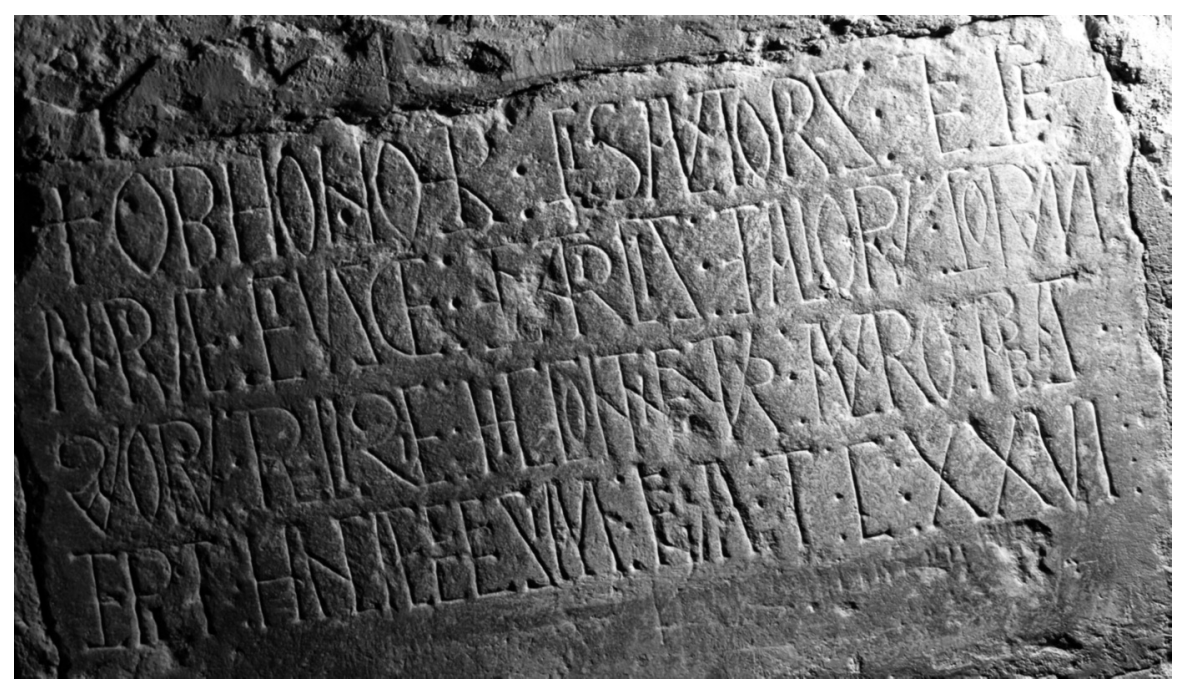

42 GARCÍA LOBO, V., La escritura visigótica publicitaria, p. 76

3 Id. Ibid., p 76 


\section{INSCRIPCIONES DE CULTURA RURAL}

Descritas por García Lobo como aquellas que «se alejan bastante de las anteriores tanto en su aspecto general como en sus caracteres alfabéticos y como en el sistema de ejecución del que desaparecen o se hacen raros los nexis y letras inscritas. ${ }^{43}$.

Destacado ejemplo de este tipo de epigrafía es la Invocatio procedente de la iglesia de Santa Isabel de Ael de Ss. IX-X (Ap. no 3), actualmente conservada en el Museo del Retablo de Burgos:

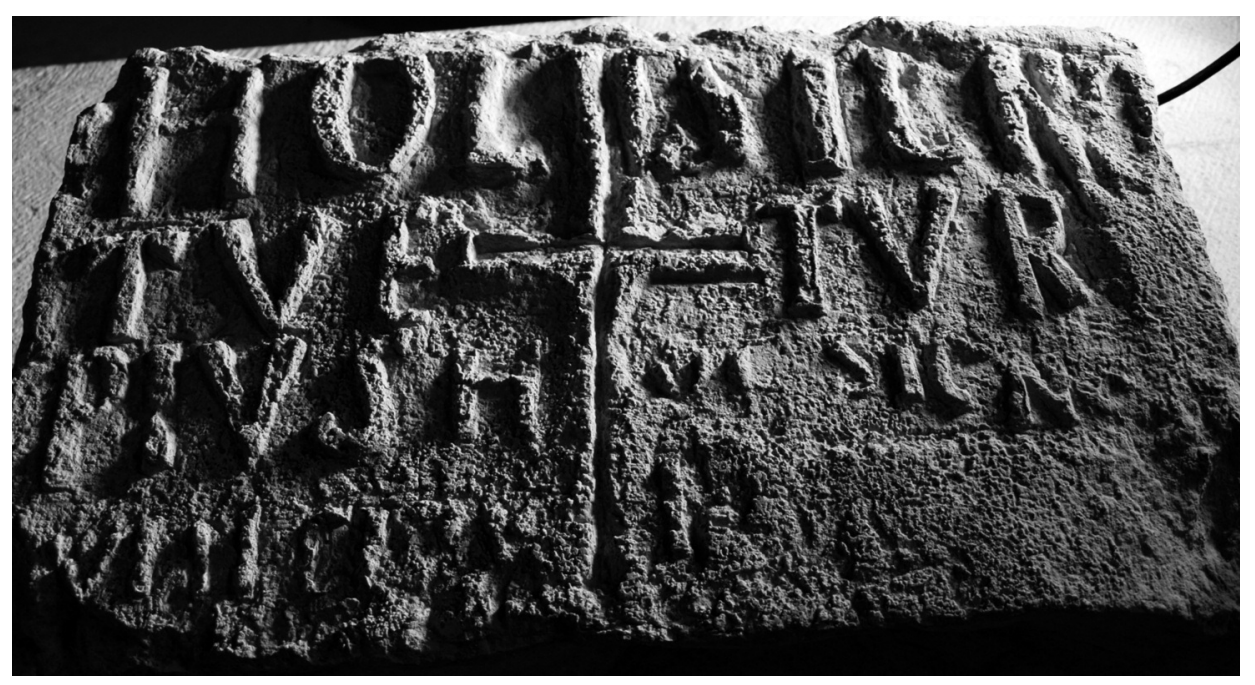

Como puede apreciarse en la inscripción, falta en ella una impaginatio en el sentido estricto que le habría dado regularidad y proporcionalidad tanto a las líneas entre sí como a las letras dentro de cada línea; además, la técnica del lapicida es torpe y, por lo tanto, el surco irregular. Como resultado tenemos un letrero carente de esa belleza que se desprende de una impaginatio y de una incisio hábilmente concebidas y ejecutadas. 



\section{APÉNDICE}

$-1-$

867

\section{Monumentum Fundationis de Ciudad de Lara.}

A. LARA DE LOS INFANTES, antigua fortificación. Inscrpción intalada en al atrio ${ }^{44}$. Procedente de la ermita de San Julián, en la Ciudad de Lara. Escr. visigótica de $45 \mathrm{~mm} \times 15 \mathrm{~mm}$, de cuidado trazado. Conserva líneas de pautado. Buena conservación. Pieza de $80 \mathrm{~cm} \times 40 \mathrm{~cm}$. Actualmente en el Museo Arqueológico Provincial de Burgos.

PUBL: Sandoval, Los cinco Obispos, pp. 283-284 y 35545; Flórez, España Sagrada, XXVII, p. 619; Gaya Nuño, La arquitectura española en sus monumentos desaparecidos, p. 133; Martínez Burgos, Catálogo del Museo Arqueológico Provincial de Burgos, p. 80; Enciclopedia del románico, Vol. IV, p. 2415

REF: Pérez de Urbel, El Condado de Castilla, pp. 210, 218 (nota 36); Castillo Iglesias, Museo de Burgos. Guía breve, p. 33.

+ IN NE DÑI GVNDESAL

BVS ET FRINDERICVS FECERUN

ISTAM CITEM SUB REGE DÑO

ADEFONSO IN ERA DCCCC

(Cruz) In nomine domini Gundesalbus et Frindericus fecerunt istam civitem sub rege domno Adefonso in Era noncetesima.

(Cruz) En el nombre del Señor, Gonzalo y Federico levantaron esta Ciudad siendo Rey D. Alfonso, en el año ochocientos sesenta y dos.

44 Conocemos su ubicación original de acuerdo a los datos que nos aportan los autores de la Enciclopedia de Románico en su publicación de la misma. Sin embargo no advierten que su ubicación actual es el Museo de Burgos.

45 Tanto Sandoval, como Flórez añaden una última frase al texto que nosotros no hemos encontrado en la inscripción conservada: “Olim Ausina, modo Lara». Ambos leen la segunda palabra como Mausina y no Ausina evitando cualquier paralelo territorial con el territorio de Ausin o Ausines. Flórez por su parte sostiene que se trata de una piedra de fábrica posterior a los hechos que narra, existiendo una discordancia entre la fecha propuesta en la inscripción y en sincronismo del reinado de cierto Alfonso, inexistente por aquellos años. Sostiene además, que aun habiendo confundido la Era por el año de Cristo, tampoco podemos demostrar la fiabilidad de la pieza, ya el año 800 dista aun en 80 de la presencia de cristianos en el territorio burgalés. Nosotros suscribimos esta opinión por la tipología gráfica que presenta la pieza conservada, ya que se trata de una escritura visigótica artificiosa y bien trazada, poco adecuada a la época de los hechos reflejados. Además, Sandoval nos dice que en origen se trataba de una piedra de letras «góticas», que fue renovada posteriormente en letras «romanas» en otra piedra que se sitió en la pared de la puerta principal de la parroquia con el mismo textos. Quizá se este el ejemplar conservado en la actualidad sin la última línea que pudo existir en el original. 
S. X

\section{Suscriptio en una de las pilastras del monasterio de Santa Eulalia.}

A. SANTA OLALLA, Iglesia de Santa Eulalia. Una de las pilastras. Escr. visigótica de $30 \mathrm{~mm} \times 30 \mathrm{~mm}$. No conserva líneas de pautado. Buen estado de conservación. Pieza de $43 \mathrm{~cm}$ x $30 \mathrm{~cm}$. Procedente del antiguo monasterio.

PUBL: Andrés Ordax, Arte Románico, p. 37; Palomero Aragón e llardia Gálligo, Rutas del Románico burgalés, IV, p. 61; AA.VV., Espinosa de los Monteros (Burgos), p. 100; Enciclopedia del románico, III, p. 2000

REF: Pérez Carmona, Arquitectura y escultura románicas en la provincia de Burgos, p. 257; Valle Barreda, Todo el Románico en Burgos, p. 358

TELLU

ABA PETRUS

PRS SC ANTO

MAISTER FU (N?)

IN N.... DALE

Tellu Abbas et Petrus presbiter et ... Sc Anto.. maister...

El abad Tello, Pedro presbítero y ... Sancho maestro...

S. IX-X

\section{Invocatio de la cruz de Santa Isabel.}

A. MUSEO DEL RETABLO DE BURGOS. Procedente de la Iglesia de Santa Isabel de Ael. Sillar exento. Escr. Visigótica en relieve de $70 \mathrm{~mm}$ x 80mm. Conserva líneas de pautado. Estado medio de conservación. Pieza de $55 \mathrm{~cm}$ x 33cm.

PUBL: Enciclopedia del Románico, III, p. 1530

REF: Valle Barreda, Todo el Románico en Burgos, p. 382; Rubio Marcos, Burgos, los pueblos del silencio, p.16

HOC SIGNO

TVE TVR

PIVS HOC SIGN[O]

VINCITV I 
Hoc signo tuetur pius, hoc signo vincitur inimicus ${ }^{46}$.

Con este signo se protege el piadoso, con este signo se vence al enemigo.

S. XI, mediados,

\section{Roboratio del Cáliz de S.to Domingo.}

A. SILOS, Monasterio de Santo Domingo, inscripción circular en la embocadura del cáliz. Escr. visigótica ${ }^{47}$. No conserva líneas de pautado. Buen estado conservación.

PUBL: Yepes, Crónica II, p. 269; Lasteyrie, Histoire de l'orfévrerie. Dépuis les temps les plus reculés jusqu'à nous jours, p. 134; Davillier, Histoire de l'orfévrerie en Espagne, au Moyen Âge et à la Renaissance, pp. 38-39; Roulin, L'ancien trésor de l'abbaye de Silos, pp. 32, 35; Gómez-Moreno, Mil joyas del arte español, p. 85; Palacios, Yarza, y Torres, El monasterio de Santo Domingo de Silos, León 1973, p. 55; Gauthier, L'atelier d'orfévrerie de Silos à l'époque romaine, pp. 380-390; Elorza Guinea, La orfébrería y los esmaltes medievales en silos, pp. 40-41; Enciclopedia del Románico, Burgos IV, p. 2584

REF: Gómez-Moreno, El arte, p.31; Martín López, Las inscripciones medievales del Monasterio de Santo Domingo de Silos, p. 473; Valle Barreda., Todo el Románico en Burgos, p. 488

+ IN NOMINE DOMINI OB HONOREM SCI SEBASTIANI DOMINICO ABBAS FECIT

In nomine dominio, ob honorem Sancti Sebastiani. Dominico Abbas fecit.

En el nombre del Señor, en honor de San Sebastián. El Abad Domingo hizo.

\footnotetext{
46 Se trata del conocido texto asociado con la monarquía asturiana de Alfonso II, el Casto, y a su vez rescatadas del Imperio Romano de Constantino. Presentes en la «Cruz de los Ángeles» y en la «Cruz de la Victoria», se convirtieron en un lema que traspasó las fronteras asturianas. Sea como fuere, más allá de la importancia del texto, la inscripción parece ponerse en relación con el territorio asturiano, bien a través de una comunidad emigrada a la zona, o bien a través de un artista encargado de materializarla.

47 La pieza esta en el Museo del Monasterio y no ha podido ser medida por estar custodiada dentro de un urna.
} 


\section{Monumentum primae petrae de la iglesia del monasterio de San Pedro de Arlanza.}

A. HORTIGÜELA, Monasterio de San Pedro de Arlanza, pilar toral oriental. Escr. visigótica. Actualmente desaparecida ${ }^{48}$.

B. SANTO DOMINGO DE SILOS, Archivo monástico, copia imitativa.

PUBL: Ferotin, Histoire, p.11

REF: Amador de los Ríos, Las ruinas del monasterio de San Pedro de Arlanza en la provincia de Burgos, p.10; Gómez Moreno, El arte románico español. Esquema de un libro, pp. 93-97; Martínez Burgos, Boletín de la Institución de Fernan Gonzalez, XXXIV; N 131, p. 555; Pérez Carmona, Arquetectura y escultura románicas en la Provincia de Burgos, p. 37; Gaya Nuño, La arquitectura española en sus monumentos desaparecidos, p. 134; Durliot, El Arte Románico en España, p. 75; Martínez de la Osa, Aportaciones parta el estudio de la cronología del románico en los reinos de Castilla y León, p. 24;; Schapiro, Estudios sobre el Románico, p. 108; Bango Torviso, El Románico en España, p. 263; ID, El Arte de Castilla y León, T II. El arte románico, p. 118; López de Guereño, Monasterio medievales premonstratenses, II, p. 395; Enciclopedia del Románico, Burgos, IV, p. 2369

$$
+ \text { ERA M }
$$

CXVIII

SŪSIT INI

CIVM

\section{HANC OPAM}

(Cruz) Era millesima centesima decima octava sumsit inicium hanc operam.

(Cruz) El año 1080 se comenzó esta obra.

\footnotetext{
48 En la publicación de José Pérez Carmona, encontramos referencias de la pérdida de esta inscripción a finales del S. XIX y de su ubicación en «uno de los machones de la izquierda de la capilla absidal del lado de la epístola». Encontrada y publicada por primera vez esta inscripción en: AMADOR DE LOS RIOS, R., Las ruinas del monasterio de San Pedro de Arlanza en la Provincia de Burgos, Madrid 1896. Advierte Carmona del error de lectura debido a los dos puntos finales, que de los Ríos debió confundir con una cuarta línea vertical para concluir la fecha en cuatro, siendo la fecha correcta la terminada en tres.

49 Se trata de la suscripción de una obra, de la iglesia, por parte de los maestrso de la misma, en este caso un padre y un hijo, pertenecientes, muy probablemente, a un taller artesanal por lo que se especifíca el parentesco entre ambos.
} 
$-6-$

1080

Suscriptio de Guillermo y su padre Osten ${ }^{49}$ del as obras de la iglesia de San Pedro de Arlanza.

A. HORTIGÜELA, Monasterio de San Pedro de Arlanza, iglesia, pilar toral. Escr. visigótica. Actualmente desaparecida.

PUBL.: Ferotin, Histoire, p. 11; Schapiro, Estudios sobre el Románico, p. 66 REF: Gudio Ricart, y Gaya Nuño, Arquitectura y Escultura Románicas, p.231; Gómez-Moreno, El arte, p. 9350; Gaya Nuño, Arquitectura española en sus monumentos desaparecidos, pp, 134-135; López de Guereño, Monasterios medievales premonstratenses, T. I, p.212 (nota 41); Enciclopedia del Románico, Burgos, IV, p. 2369

\author{
+GVILLELMEZ \\ ET OSTEN PR EIVS \\ FECRVNT HANC \\ OPERA GVVERNAÑ \\ DOMO ABRA VICENT \\ IN ERA M [C XVIII]
}

(Cruz) Guillelmez et Osten, pater eius, fecerunt hanc operam guvernante domo abba Vicentius, in Era millesima centesima dicima octava.

(Cruz) Guillermo y su padre Osten hicieron esta obra, siendo abad de la casa Vicente ${ }^{51}$, el año (1080).

50 Goméz-Moreno en su edición lee -en caracteres mayúsculos- el nombre ETOSTEM, por Osten, que nosotros hemos recogido en el resto de publicaciones. Es la lectura de Ferotín que también es copiada por López de Guereño.

51 Incluir el abadiazgo u obispado como método de datación junto con la fecha numérica es un recurso habitual en epigrafía para fortalecer la credibilidad de los datos expuestos. El abad Vicente I gobernó en Arlanza entre los años 1074-1096, lo que concuerda con la suscripción de la obra por parte de estos dos maestros laicos. Cf. SAN MARTíN, J., Arlanza, San Pedro de: DHEE, III, Madrid, 1972, p. 1518 
1088

\section{Monumentum primae petrae de la iglesia de San Salvador de Escaño por el abad Álvaro.}

ESCAÑO, Iglesia de San Salvador, sillar del muro muy próximo a la cabecera en la parte izquierda del muro a $40 \mathrm{~cm}$ del suelo, Escr. visigótica de $50 \mathrm{~mm} x$ $16 \mathrm{~mm}$. No conserva líneas de pautado. Buen estado de conservación. Pieza de $56 \mathrm{~cm} \times 30 \mathrm{~cm}$.

PUBL: Ruiz Vélez, El arte románico en el norte burgales, p. 54; Palomero Aragón, e Ilardia Gálligo, Las rutas del Románico burgalés, p. 43; Enciclopedia del Románico, Burgos, III, p. 1741

REF: Valdivielso Ausín, Rutas del Románico en la provincia de Burgos, p. 91; Lacanda Esteban, El análisis arqueólogico de la iglesia de San Salvador de Escaño, p. 342; Valle Barreda, Todo el Románico en Burgos, p. $330^{52}$

+ OB HONORE : SCI SALVATORIS : ET SCE

MARIAE:EIVS GE : NITRICIS:ET ALIORV:SC RVM

QVORVM:RELIQVIE:HIC:CONTINENTVR:ALVARO:ABBAS ${ }^{53}$

CEPIT:HANC:AECCLESIAM:IN ERA ${ }^{54: T: C: X X V I ~: ~}$

(Cruz) Ob honore sancti Salvatoris et sancte Mariae eiusdem Genitricis et aliorum sanctorum quórum reliquia hic continentur Alvaro abbas cepit hanc aecclesiam in Era millesima vigesima sexta.

El año mil ochenta y ocho el abad Álvaro ${ }^{55}$ comenzó esta iglesia, en honor del Salvador y de su Madre Santa María y de los Santos cuyas reliquias aquí se contienen $^{56}$.

52 Los autores de esta obra nos ofrecen la siguiente traducción: «En honor de San Salvador y de su misma Madre Santa María y de los otros santos cuyas reliquias aquí se contienen, el abad Álvaro construyó esta iglesia en la Era de 1126». A nosotros nos parece más correcto el orde de traducción que le hemos dado, por cobrar más sentido lógico. Cf. VALLE BARREDA, C., Todo el Románico en Burgos, Aguilar de Campoo 2001, p. 330

${ }^{53}$ La S final de ABBAS se encuentra nexada a la A final. Palomero e llardia no la leen, incorporándola como abreviada.

${ }^{54}$ Félix Palomero e Magdalena llardia tampoco contemplan la A final de Era, que nosotros vemos clara en nuestra lectura.

55 De nuevo encontramos la figura de un abad ligado a un centro monástico remoto del que no hemos encontrado referencias. En el DHEE no hemos encontrado ninguna entrada relacionada con Escaño y tampoco encontramos abades de este nombre en los grandes centros: Ni Arlanza, ni Cardeña, ni Oña, ni Silos parecen tener entre sus regentes a ningún Álvaro. De nuevo, podríamos pensar que el hecho de que exista una inscripción donde suscribe un abad es motivo suficiente para afirmar que existió un primitivo cenobio de efímera vida. Sin embargo, en el estudio publicado por Lecanda, vemos como el análisis arqueológico es concluyente sobre las diferentes estructuras que existieron en Escaño, y parece que 
$-8-$

S. XI

Epitaphium sepulcrale de Munio González ${ }^{57}$.

A. MUSEO DE BURGOS. Procedente del monasterio de San Pedro de Valeránica en Todómar. Cubierta de sepulcro. Escr. visigótica de $90 \mathrm{~mm} \times 35 \mathrm{~mm}$. No conserva líneas de pautado. Mal estado de conservación. Pieza de $95 \mathrm{~cm}$ x $10 \mathrm{~cm}$.

PUBL: Castillo Iglesias, Museo de Burgos. Guía breve, p. 33; Enciclopedia del Románico, Burgos, II, p. 812

REF: Valle Barreda, Todo el Románico en Burgos, p. 232

$$
\text { OBIT IN PACE FAMVLVS Dİ MVNNIV GVNDI[SALVI] }
$$

Obiit in pace famulus Dei Munniu Gundisalvi

Murió en paz el siervo de Dios Muño González.

$$
-9-
$$

S. XI ex. - S. XII inc.

\section{Suscriptio del maestro cantero Pedro.}

A. HORTIGÜELA, Ermita de San Millán, muro sur de la nave, sillar. Escr. visigótica de $35 \mathrm{~mm} \times 10 \mathrm{~mm}$. No conserva líneas de pautado. Buen estado de conservación. Inscripción que ha sido retocada. Pieza de $53 \mathrm{~cm} \times 25 \mathrm{~cm}$.

PUBL: Enciclopedia del Románico, Burgos, IV, p. 2350

REF: Valle Barreda, Todo el Románico en Burgos, p. 458

\section{PETRVS}

MAGIS

TER FE

no podemos hablar nunca de estructura monacal. Cf. LECANDA ESTEBAN, J. A., El análisis arqueológico de la iglesia de San Salvador de Escaño: resolución de problemas arquitectónicos y aprximación histórica al primer románico burgalés: en Actas de V congreso de Arqueología Medieval Española, Valladolid 22-27 de Marzo de 1999, Valladolid 2001, pp. 341-349

56 La mayoría de los autores que han hecho referencia a esta iglesia, la consideran como la más antigua fechada del románico burgalés, sirviendo de data para otras pertenecientes a este estilo del románico en la provincia.

57 Al igual que sucede con la estela anterior, no resulta fácil encontrar referencias del personaje. Quizá pueda tratarse de algún miembro de la familia conda de Fernán González, quien favoreció notablemente a este centro. Cf. MORAL, T., Berlanga o Baleránica, San Pedro: DHEE, III, Madrid 1972, p. 1530 


\begin{abstract}
CIT OC I
$\hbar E S^{58} \mathrm{Q}[\mathrm{UI}] \mathrm{TI}$

TVLABIT 59

+ Petrus magíster fecit oc. Ihoannes qui titulabit.

+ El maestro Pedro hizo esto. Juan que lo escribió
\end{abstract}

$-10-$

1105

Epitaphium sepulcrale de la sierva de Dios Godo ${ }^{60}$.

A. HORTIGÜELA, Monasterio de San Pedro de Arlanza. Losa sepulcral, integrada en el llamado «sepulcro de Mudarra». Escr. visigótica de $82 \mathrm{~cm}$ x $55 \mathrm{~cm}$. No conserva líneas de pautado. Buen estado de conservación. Pieza de $195 \mathrm{~cm} x$ $13 \mathrm{~cm}$. Actualmente en la Catedral de Burgos (claustro).

PUBL: Amador de los Ríos, España, su monumentos y artes, su naturaleza e historia, p. 89561; Huidobro, Contribución al arte visigótico en Castilla, p. 83; Huidobro, La Catedral de Burgos, p. 7462; Gudiol Ricart, y Gaya Nuño, Aquitectura, p.233; Pérez Carmona, Arquietectura y escultura Románicas de la provincia de Burgos, p. 46; Gaya Nuño, Arquitectura española en sus monumentos desaparecidos, p. 136; Lojendio y Rodríguez, La España Románica, Vol. I, p. 356; Enciclopedia del Románico, Burgos, IV, p. 2377

REF: Gómez-Moreno, El arte, p. 96; Valdivielso Ausín, Rutas del románico en la provincia de Burgos, p. 32

58 Aunque no son claras las letras del nombre propio, el sentido de la inscripción nos pide reconocer en estos caracteres un nombre propio en nominativo. Debido a las letras más claras que sí se reconocen, creemos que «lhoannes» es el nombre del suscriptor — rogatario— de la inscripción y Pedro el maestro de la obra y autor de la inscripción.

59 Los autores de la Enciclopedia del Románico en Castilla y León dan el siguiente texto a partir de la 4 linea: CITOB / RECOTI / TVLABEI. Se debe a una mala lectura, puesto que la «Q» esta invertida hacia el lado izquierdo e induce a confusiones.

60 Existen problemas para identificar a este personaje. En la obra de Carmona se nos hace mención a una Doña Goda, hija de Lope Iñiguez de Marañon y mujer del conde Don Marcerlo, señor de Álava, Marañón, Pancarbo y Temiño. Sin embargo nos dice que esta mujer debió morir sobre el año 87 y debió ser enterrada en Oña, de cuyo monasterio habría sido gran protectora. Exiten también otras candidatas: Godo, hija de Gonsalo Salvadórez Rico; Godo, hija de Don Gonzálo Nuñez de Lara y Godo hija de García Armíldez. Todas ellas presentarían problemas cronológicos respecto a la data que pone en su sepulcro o bien con la relación existente con el monasterio de San Pedro de Arlanza.

${ }_{61}$ Amador de los Ríos, da una lectura errónea de la palabra FAMULA, leyendo FATA.

62 En la obra de Huidobro solo se recoge la noticia del traslado del sepulcro de Godo a la Catedral de Burgos y su origen en el monasterio de San Pedro de Arlanza. 
:HOC: IN LOCO:REQVIESCIT :FAMŁA :DEI :GODO :II : NÑ : FBRI :IN :ERA: M:

C: XLIII:

Hoc in loco requiescit famula Dei Godo, (qui obiit) secundo nonas februarii, in Era millesima centesima quadragesima tertia.

En este lugar descansa la sierva de Dios Godo, que murió el día cuatro de febrero del año 1105.

$-11-$

1114

Consecratio de la iglesia de San Esteban y Santa Coloma.

A. RIOCAVADO DE LA SIERRA, Iglesia de Santa Coloma, capitel del lado de la epístola del arco central. Escr. carolina con alguna reminiscencia visigótica de $28 \mathrm{~mm} \times 22 \mathrm{~mm}$. Conserva línea de pautado. Buen estado de conservación salvo en el inicio. Pieza 43,5cm x 26cm.

PUBL: Palomero, e llardia, Las rutas del románico burgalés, I, p. 31; Enciclopedia del Románico, Burgos, IV, p. 2503

REF: Valdivielso Ausín, Rutas del románico en la provincia de Burgos, p. 162; Valle Barredo, Todo el Románico en Burgos, p. 477

\author{
$[\ldots \ldots \ldots \ldots]^{63}$ \\ AVG[VST]I \\ IN ERA M C LII \\ PASCAŁ EPS DEDIC[AVIT] \\ HOC TEMPLV IN HONO \\ RE SCĪ : STPHI \\ MR : ET SCË CO \\ LVBE VR : ET ALIO \\ RV PLVRIMOR \\ SCOR MRM \\ CŌFR AQ; VIRG
}

\footnotetext{
63 Aunque los autores de la enciclopedia no indican que falte nada, pensamos que debe faltar una línea con los numerales del día del mes.
} 
[............. augusti, in Era millesima centesima quinquagesima secunda, Pacalis episcopus dedicavit hoc templum in honore sancti Stephani martiris et sancte Columbe virginis et aliorum plurimorum sanctorum martirum, confesorum et virginum.

[El día......] de agosto del año 1114 el obispo Pascual ${ }^{64}$ consagró este templo en honor de san Esteban mártir y a santa Coloma virgen y a otros muchos santos mártires, confesores y vírgenes.

$1132(1122)$

\title{
Consecratio de la Iglesia de Santa Eulalia.
}

A.SANTA OLALLA, Iglesia de Santa Eulalia. Sacristía. Un sillar y parte de otro del exterior del muro meridional en su parte más alta, pegada al techo. Escr. visigótica de $40 \mathrm{~mm} \times 20 \mathrm{~mm}^{65}$. No conserva líneas de pautado ${ }^{66}$. Buen estado de conservación. Pieza de $108 \mathrm{~cm}$ x $40 \mathrm{~cm}$.

PUBL: Pérez Carmona, Arquitectura y escultura románicas en la provincia de Burgos, p. 257; Palomero, e llardia, Las rutas del románico burgalés, IV, p. 6167; Palomero, et Alii, Espinosa de los Monteros, p. 100; Enciclopedia del románico, Burgos, III, p. 199968

REF: Sáinz Sáiz, Las Merindades. Montañas de Burgos, p. 65; Valdivielso Ausín, Rutas del románico en la provincia de Burgos, p. 89; Valle Barredo, Todo el Románico en Burgos, p. 358

\author{
ERA MCLX [X] FVIT \\ CONSECRATA ECLA \\ SCA EVLALIA NOTVVM \\ DIE IDUS MARCII GUNDISALVVS \\ PRSBR ET PEREGRINUS AB EPO \\ MICHAEL TIRASONA FECIT CONSE
}

\footnotetext{
${ }^{64}$ Obispo Pascual, Obispo de Burgos entre 1114 y 1118.Cf. MANSILLA, D.,Burgos, Diócesis de: DHEE, III, Madrid 1972, p. 294

${ }^{65}$ Esta medida es la media, ya que las letras oscilan enormemente en su altura y ancho.

66 Únicamente conserva un enmarque en el extremo derecho que parece de factura posterior.

67 Félix Palomero en su edición solo lee la $\mathrm{O}$ final de episcopo, reconstruyendo en la transcripción el resto de la palabra.

68 Los autores de la Enciclopedia del Románico, no tiene en cuenta el hueco machacado al final de la data leyendo únicamente una $\mathrm{X}$.
} 


\section{SECRARE}

Era millesima centesima sexagesima fuit consecrata ecclesia Sancte Eulalia notuum die idus mercii Gundisalvus presbiter et peregrinus ab episcopo Michael Tirasona $^{69}$ fecit consecrare.

El año 1132 fue consagrada esta iglesia de Santa Eulalia, en el señalado día de los idus de marzo. Gonzalo, presbítero y peregrino la hizo consagrar por el obispo Miguel de Tarazona.

1139, agosto, 24.

\section{Epitaphium necrologicum de cierto Jimeno ${ }^{70}$.}

A. HORMICEDO, Iglesia de San Quirico y Santa Julita, portada, sillar. Escr. visigótica $^{71}$. Buen estado de conservación. No conserva líneas de pautado.

PUBL: Enciclopedia del Románico, Burgos, Vol. I, p. 29672; Valle Barreda, Todo el Románico en Burgos, p. 100

IX K SE

TEMBRIS

OBITT SEMEN'

ERA T CLX

$X V I I A^{73}$

Tertio kalendas setembris obiit Semenus ${ }^{74}$, Era millesima centesima septuagesima septima.

El día 30 de agosto del año 1139 murió Jimeno.

69 Miguel de Tarazona, obispo entre 1118-1151. Asistió a la reconquista de la ciudad. ZAMORA, F., Tarazona, Diócesis de: DHEE, IV, Madrid 1975, p. 2526

70 No hemos encontrado referencia alguna a este personaje. Pudiera tratarse de un personaje relevante del viejo municipio o una clérigo ligado al monasterio de Covarrubias, de quien dependió Hormicedo, o del monasterio de San Cristobal de Villadiego, del que por esos años esta documentada cierta actividad ligada a la catedral de Burgos.

71 Debido a la actual ubicación de la inscripción no hemos podido tomar medidas.

72 En su publicación, los autores dela Enciclopedia del románico, advierte de que el numeral $\mathrm{X}$ de la última línea es algo dudoso por encontrares recubierto con la argamasa. A pesar de la poca certidumbre de la letra, nosotros nos inclinamos a pensar que si existe, por el trazado de los renglones y la posición de la letra en el texto. Mantenemos la fecha de 1139.

73 Esta letra final se incluye en algunos textos expigráficos para darnos el ordinal de la Era.

74 El texto epigráfico presenta la particularidad de la M invertida en el nombre del difunto. Las limitaciones tipográficas nos impiden editar este hecho. 
$-14-$

S. XII, mediados ${ }^{75}$

\section{Suscriptio de la Iglesia de San Miguel de Tartalés.}

A. TARTALÉS DE CILLA, Iglesia de San Martín, arco que da paso a la nave del cabecero, cimacio y el otro lado del Evangelio. Escr. visigótica de $25 \mathrm{~mm} x$ $17 \mathrm{~mm}$. No conserva líneas de pautado. Inscripciones fragmentadas. Buen estado de conservación ${ }^{76}$. Piezas de $10,5 \mathrm{~cm} \times 3,5 \mathrm{~cm}$ y $39 \mathrm{~cm} \times 3,5 \mathrm{~cm}$.

PUBL: Enciclopedia del Románico, Burgos Vol. III, p. 2033

REF: Palomero, F. e Ilardia, M., Las rutas del románico burgalés, Vol. III, p. 63

$$
\text { (cimacio): ....VIMAR[ANVS] }{ }^{77}
$$

(evangelio): +RVDERIGVS GALECIANO FECIT

(línea superior): IEG

...Vimaranus, Rodericus Galeciano fecit Iglesiam.

...Vimarano, Rodrigo Galeciano hizo (esta) Iglesia.

$1147^{78}$

\section{Monumentum plantationis de un huerto por cierto Pascasio ${ }^{79}$.}

A. CRESPOS, Iglesia de la Inmaculada Concepción. exterior, flanco derecho de la portada, en un sillar de un contrafuerte. Escr. visigótica de $70 \mathrm{~mm} \times 30 \mathrm{~mm}$. No

75 Los autores de la Enciclopedia - expertos historiadores del arte- nos ofrecen esta fecha para darta en conjunto arquitectónico de Tartalés. Desde el punto de vita paleográfico nos parece una fecha muy tardía para la inscripción, ya que el módulo alargado de las letras, el último trazo rectilineo de las «R», la «T», típica con bucle a la izquierda o la «N» con el trazo horizontal que arranca de la mitad del primer trazo vertical son elementos característicos de una escritura visigótica pura que adelantaría la fecha de ejecución practicamente en un siglo. También puede tratarse de rogatarios de tradición visigótica aun acostumbrados a escribir en este tipo de escritura.

76 Se trata de inscripciones realizadas en el mismo momento y por la misma mano. Coindicen en estilos y tamaños. Se conserva la caja de escritura con trazos muy marcados. Conservan líneas de pautado horizontales la inscripción del cimacio y la del evangelio. La inscripción superpuesta a ésta última carece de él. Buena caligrafía.

77 Aquí los autores de la Enciclopedia del Románico solo aciertan a leer hasta la M. Nosotros vemos una $\mathrm{A}$ nexada al último trazo de la $\mathrm{M}$ y creemos que la última letra es un $\mathrm{R}$ a pesar de no conservarse la parte superior del cuerpo de la letra.

78 La última letra que nosotros leemos en la data es una V. Pérez Carmona, los autores de la Enciclopedia del Románico y Palomero e llardia se decanta por una I. Nosotros variamos la fecha de la misma en cuatro años.

${ }_{79}$ No hemos podido localizar en la documentación a este personaje. Sin embargo, hemos llegado a la conclusión de que puede tratarse de un personaje que entregó el huerto en donación a la iglesia de 
conserva líneas de pautado. Buen estado de conservación. Pieza de $55 \mathrm{~cm}$ x $28 \mathrm{~cm}$.

PUBL: Pérez Carmona, Arquitectura y escultura Románicas de la provincia de Burgos, p. 38 ${ }^{80}$; Martínez de la Osa, Aportaciones para el estudio de la cronología del románico en los reinos de Castilla y León, p. 48 ${ }^{81}$; Palomero, e llardia, Las rutas del románico burgalés, IV, p. 8882; Enciclopedia del Románico, Burgos, III, p. 1705; García Morilla, La enigmática inscripción de la iglesia de la Inmaculada Concepción de Crespos (en prensa)

REF: Valdivielso Ausín, Rutas del románico en la provincia de Burgos, p. 6383; Valle Barreda, Todo el Románico en Burgos, p. 329

\title{
V K MAI PASCASIVS \\ PLANTAVIT ORTI \\ IN ERA TCLXXXV
}

\author{
$\checkmark$ Kalendas mai Pascasius plantavit orti, In Era millesima centesima optuage- \\ sima quinta.
}

El 27 de abril de 1147 Pascasio plantó (este) ${ }^{84}$ huerto.

\footnotetext{
Crespos a cambio de ennoblecer su alma, siendo perpetuada su persona en una inscripción conmemorativa. Cf. GARCÍA MORILLA, A., La enigmática inscripción de la iglesia de la Inmaculada Concepción de Crespos: Homenaje al Prof. Ruiz Asencio (en prensa)

${ }^{80}$ El padre Carmona nos advierte de que se trata de la primera iglesia burgalesa fechada en el S. XII. Además señala que Ariano —-como él lee en lugar de Pascasio-, podría ser el nombre del constructor o de quien costeo las obras.

${ }_{81}$ Martínez de la Osa sigue la lectura propuesta por Pérez Carmona, cometiendo los mismos errores de lectura.

82 Palomero e llardi comenten los mismos errores de lectura que el padre Carmona, muy probablemente por tomar directamente el texto de su publicación. Confunden el nombre de Pascasio y la fecha.

83 Sigue la lectura del padre Carmona, con los mismos errores de lectura.

$84 \mathrm{Sin}$ duda la inscripción hace referencia a un huerto situado en las inmediaciones de la iglesia. Al igual que encontramos en muchas Consecrationes a las que acompaña el pronombre ista, iste, istam, haciendo hincapié en que se alude a la iglesia que contiene la inscripción, en este caso, el cercado debía estar próximo al muro meridional de la iglesia.
} 


\section{CORPUS FOTOGRÁFICO}

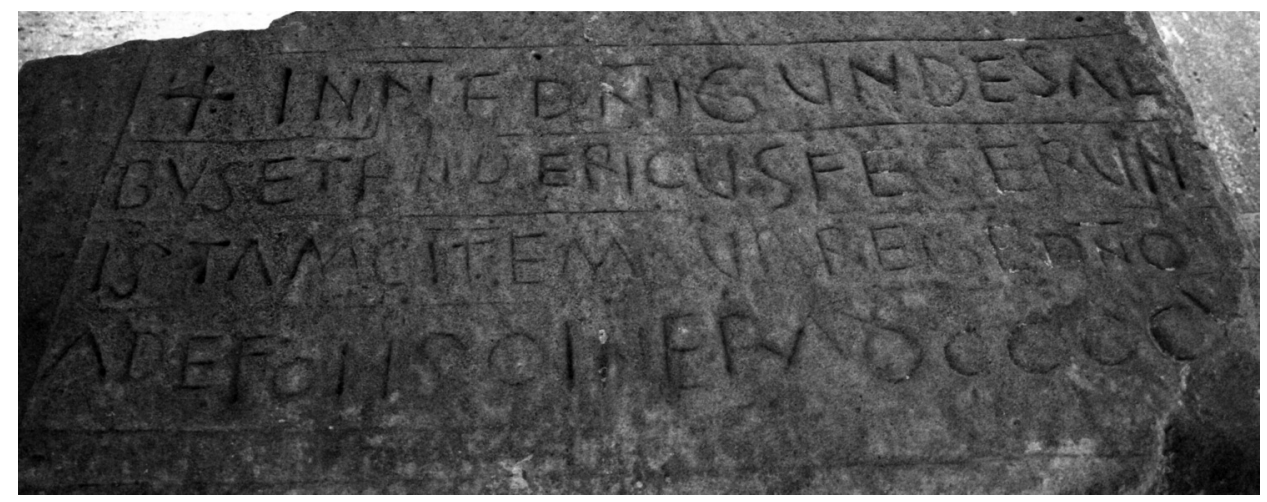

Lám. I. Monumentum fundationis de Ciudad de Lara. MUSEO BURGOS (Ap. no 1)

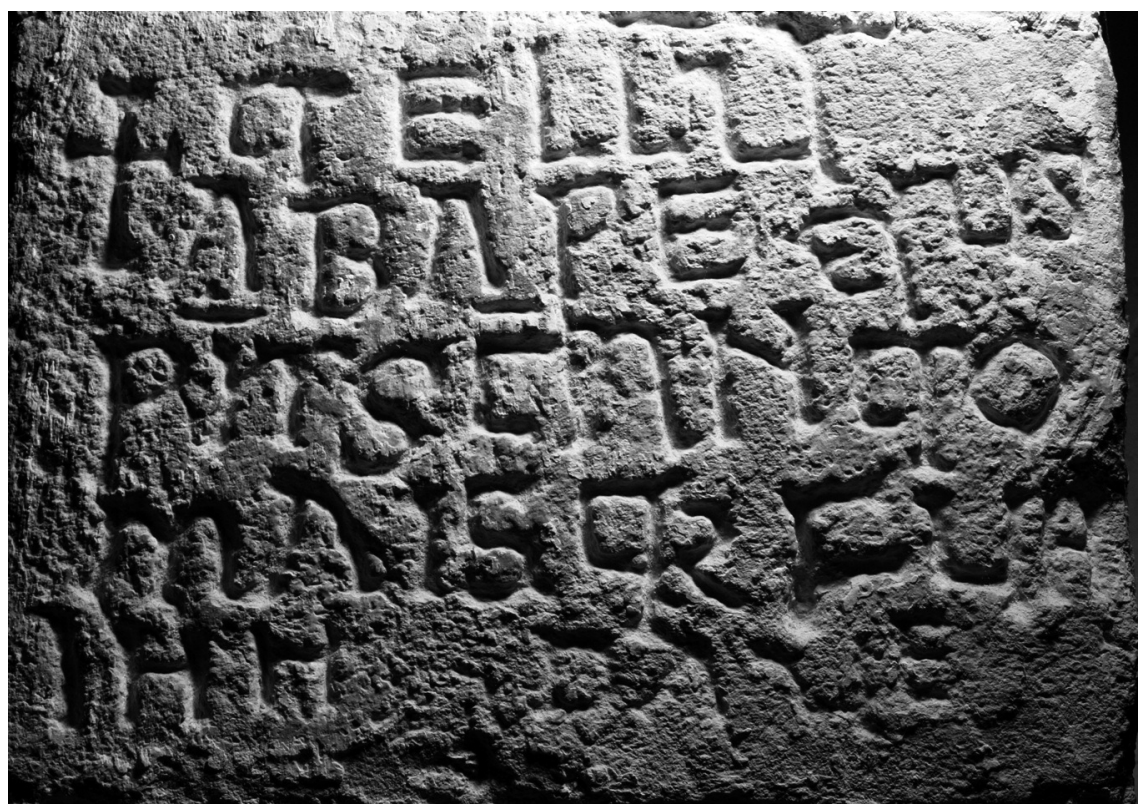

Lám. II. Suscriptio del monasterio de Santa Eulalia. SANTA OLALLA (Ap. no 2) 


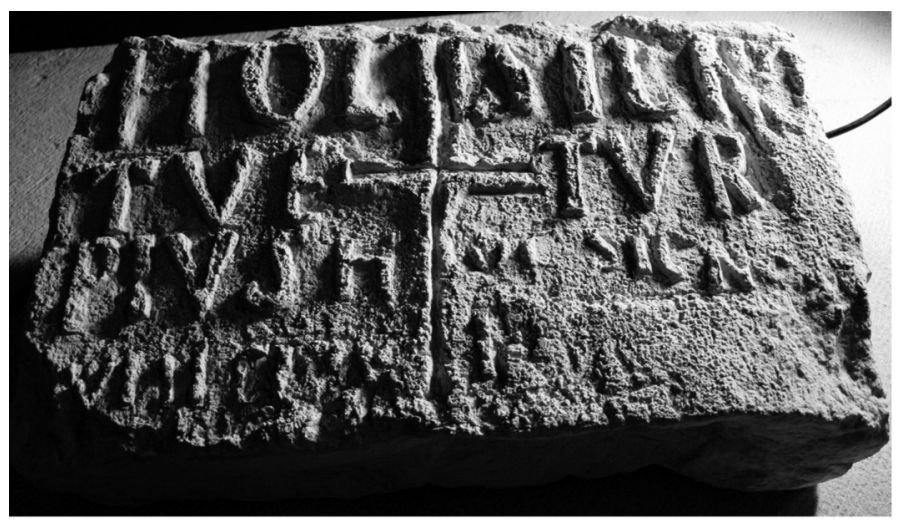

Lám. III. Invocatio Cruz de Santa Isabel de Ael. MUSEO RETABLO. (Ap. no 3)

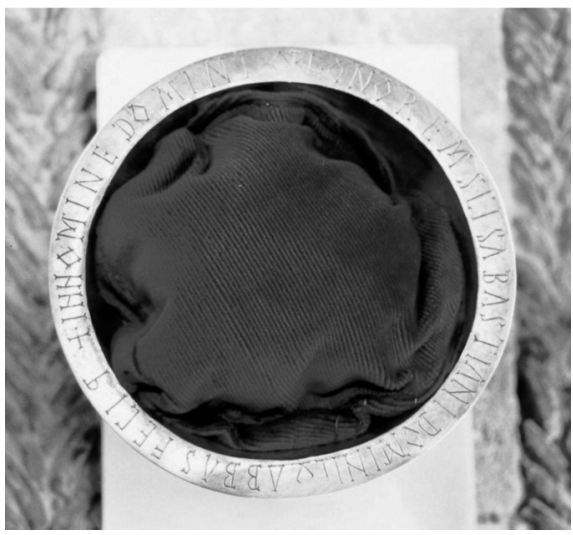

Lám. IV. Roboratio cáliz Santo Domingo. SILOS. (Ap. no 4)

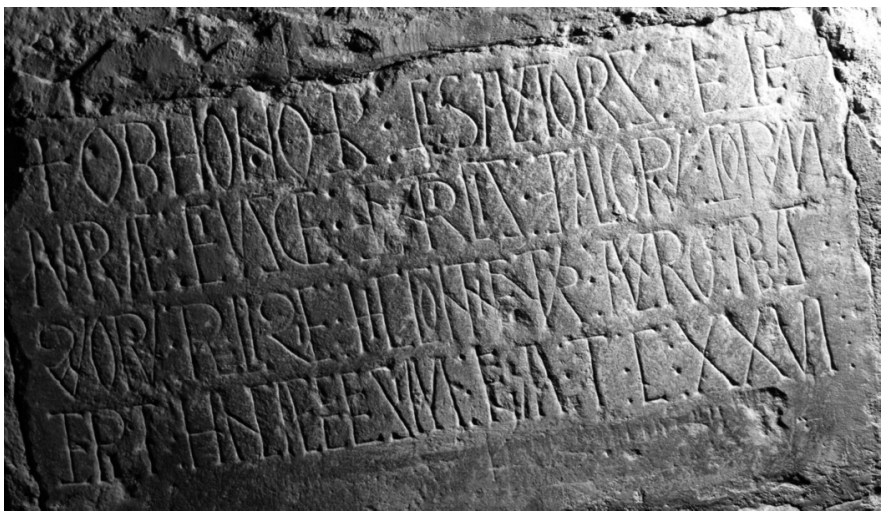

Lám. V. Monumentum primae petra de San Salvador. ESCAÑO. (Ap. no 7) 


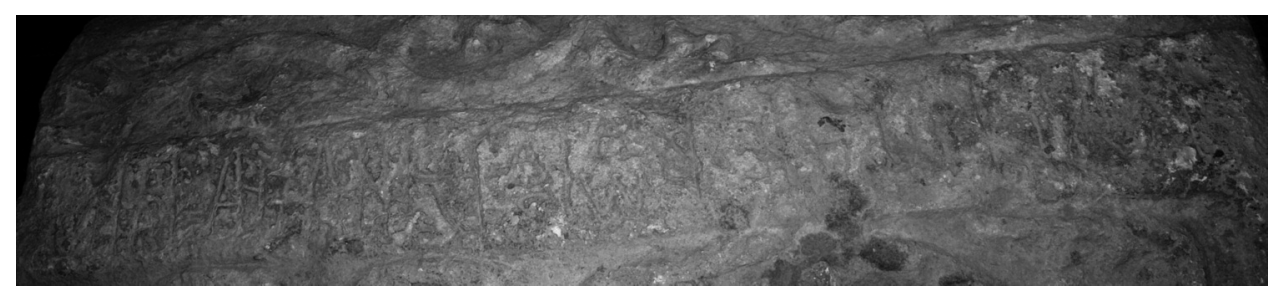

Lám. VI. Epitaphium sepulcrale de Munio González. MUSEO BURGOS. (Ap. n‥ 8)

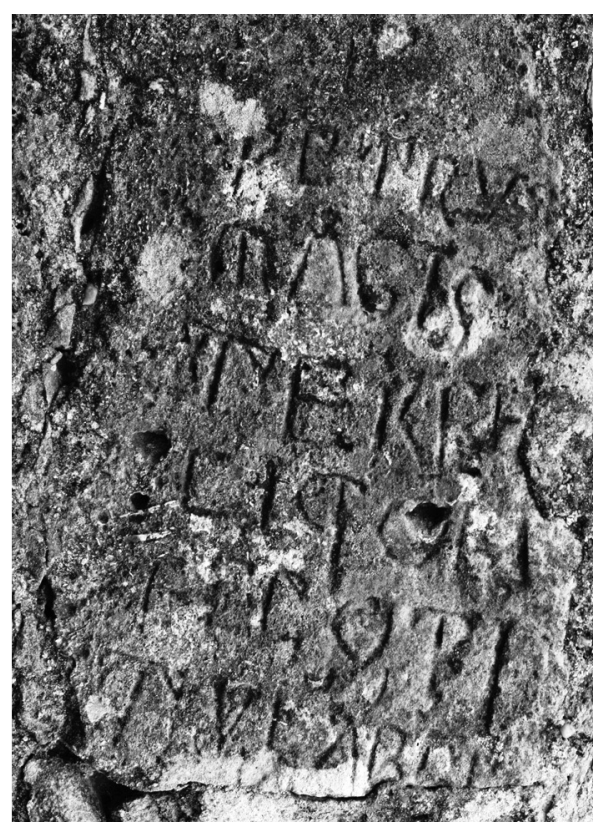

Lám. VII. Suscriptio del maestro Pedro de San Millán. HOTIGÜELA: (Ap. no. 9)

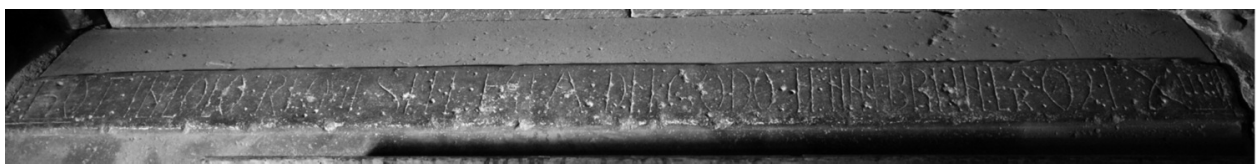

Lám. VIII. Epitaphium Sepulcrale de Godo. CATEDRAL DE BURGOS. (Ap. no 10) 


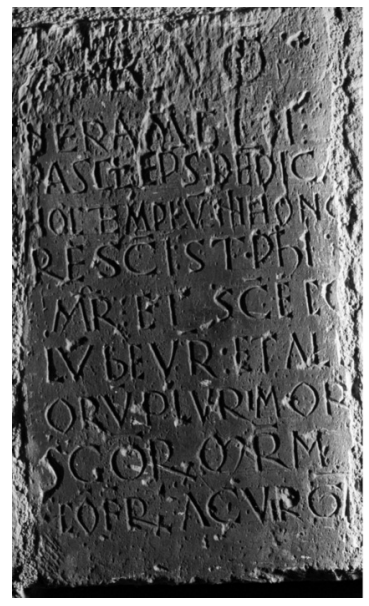

Lám. IX. Consecratio de la iglesia de San Esteban y Santa Coloma. RIOCAVADO. (Ap. no. 11)

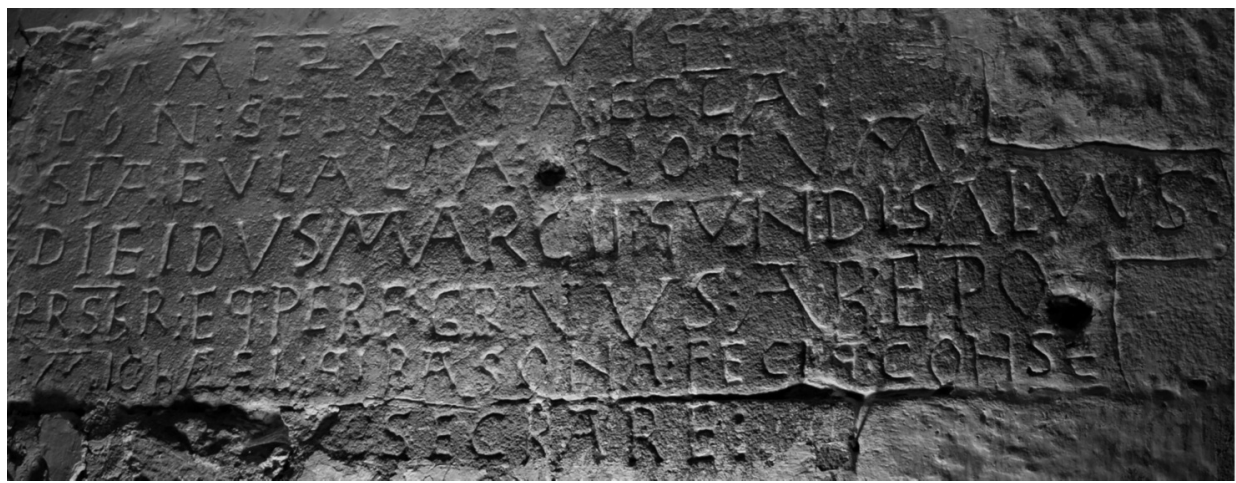

Lám. X. Consecratio de la iglesia de Santa Eulalia. SANTA OLALLA. (Ap. no 12)

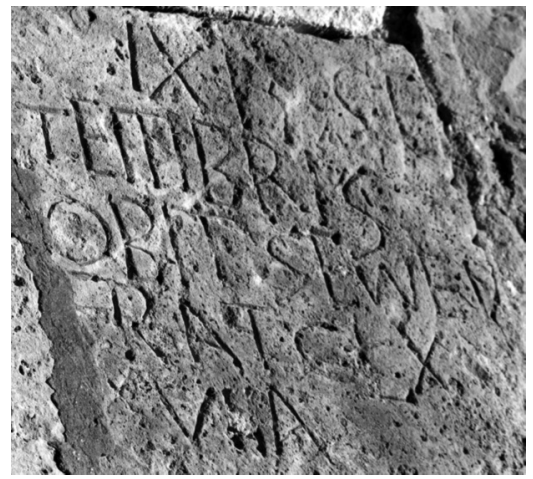

Lám. XI. Epitaphium Necrologicum de Semenus. HORMICEDO. (Ap. no 13) 

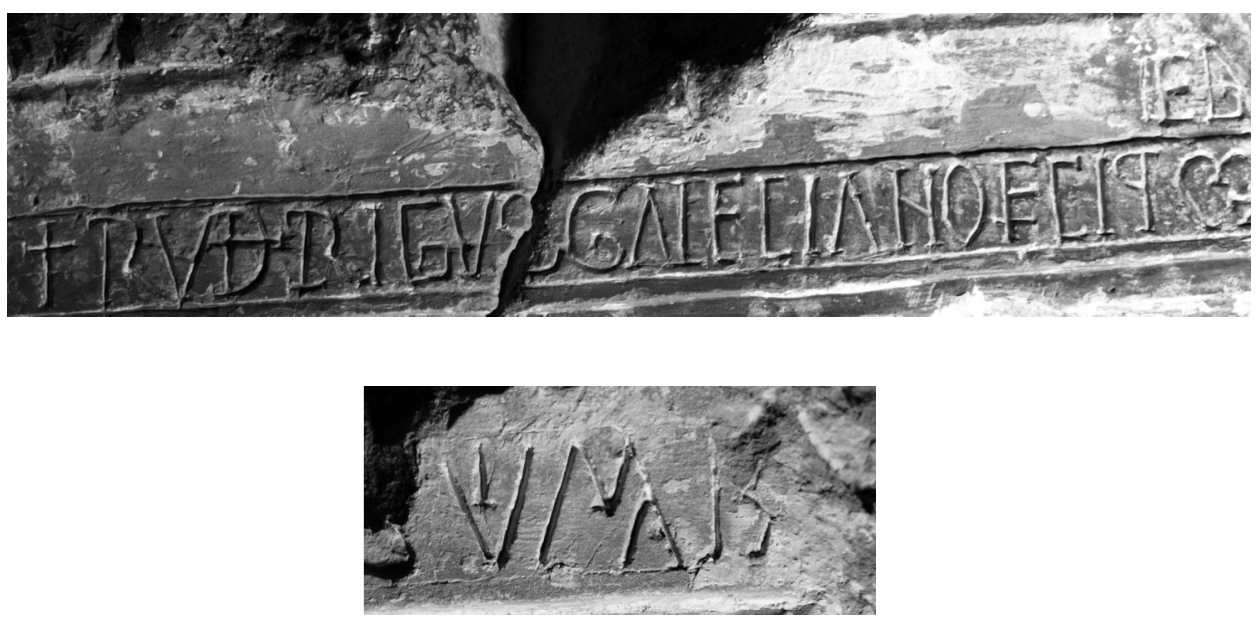

Lám. XII. Suscriptio de la iglesia de San Miguel. TARTALÉS DE CILLA. (Ap. no 14)

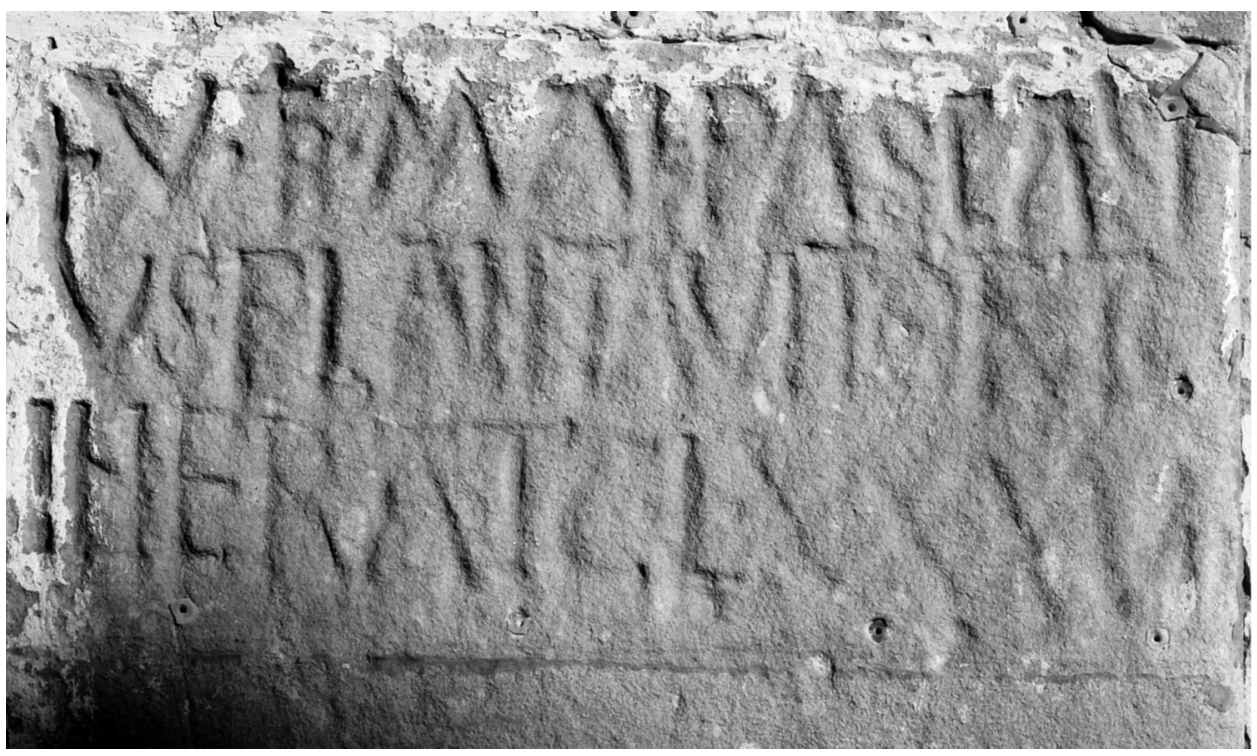

Lám. XIII. Monumentum plantationis de un huerto por Pascasio. CRESPOS. (Ap. no 15) 